\title{
What's in an object file? Evidence from priming studies
}

\author{
ROBERT D. GORDON and DAVID E. IRWIN \\ University of Illinois at Urbana-Champaign, Urbana, Illinois
}

\begin{abstract}
Six experiments were conducted to investigate the nature of the contents of object files, temporary representations that store information about objects. Experiment 1 used a lexical priming paradigm with a lexical decision task, in which the prime and target could appear in either the same or different locations. The results indicated a greater priming effect when the prime and target appeared in the same location than when they appeared in different locations (object-or location-specific priming). Experiment 2 replicated these findings for objects that changed position during the display. Experiment 3 demonstrated that these findings reflected the inclusion of abstract identity information, rather than physical form, in object files. Three additional experiments tested for the presence of three types of semantic information (related concepts, semantic features, and category membership) in object files. No object-specific priming effects were found. Taken together, these experiments suggest that an object file includes identity information, but not semantic information. Implications of the results for object file theory are discussed.
\end{abstract}

Our visual world is filled with objects that constantly change their position or appearance. The size, shape, and position of an object on the retina change every time the object moves or we move our eyes. Yet despite these constant stimulus changes, objects in motion maintain continuity; likewise, objects are seen as continuous when viewed across saccades, even though much of their appearance may change. How is it that the visual system is able to preserve the continuity of objects? Why don't we see a rotated object as completely novel, rather than as an alternate view of a previous object?

These issues are particularly important in light of recent evidence that suggests a special role for objects in perception. For example, several researchers have suggested that visual attention can be distributed to individual objects within a scene, regardless of the spatial characteristics of the object. For example, Kramer and Jacobson (1991) provide evidence that objectness can override spatial proximity. In their experiments, flankers interfered more when they appeared within the same object as did the target than when they appeared in a different object, despite the fact that the flanker-target separation was held constant. In another important experiment, Duncan (1984) presented subjects with stimuli consisting of a slanted line superimposed on a rectangle; the subjects were required to make a judgment about two dimensions of one of the

The research reported here was part of a master's thesis completed by R.D.G. and was supported by NSF Grant SBR 93-09564 to D.E.I. We thank Rachel Andrews, Kyle Cave, Art Kramer, Lester Krueger, Gordon Logan, Leonard Trejo, Chris Wickens, and Jeremy Wolfe for their comments on this research, and Caprice Anderson and Sang Du for their assistance with data collection. Portions of these data were reported at the 1995 Annual Meeting of the Midwestern Psychological Association, Chicago. Please address correspondence to R. D. Gordon, Department of Psychology, University of Illinois, 603 E. Daniel St., Champaign, IL 61820 (e-mail: rgordon@s.psych.uiuc.edu). objects, or about one dimension of each object. Subjects responded more quickly when making the judgments about a single object, suggesting that they were able to attend to one object and ignore the superimposed object in the display. Finally, Baylis and Driver (1993; Baylis, 1994) have demonstrated that subjects are able to judge the relative positions of two apices better when they are part of the same object than when they are a part of different objects. These experiments all provide support for the notion that objects play an important role in scene perception.

The relative importance of objects in visual processing underscores the need for a mechanism that maintains information about objects. At present, it is unclear how the visual system preserves object continuity despite stimulus changes. One possible explanation, known as object file theory, has recently been proposed by Treisman and her colleagues (Kahneman \& Treisman, 1984; Kahneman, Treisman, \& Gibbs, 1992; Treisman, 1988, 1992). According to this theory, when attention is directed to an object in the visual field, a temporary representation of that object (an object file) is created. This file gathers and maintains information about the object it represents. When the object changes in some way, it is compared with the contents of the previous object file; if it is similar, the object is seen as continuous. If it is much different, the existing object file is discarded, and a new one is created to represent the new object. In this case, there is no sense of object continuity; rather, the object is seen as distinct from previous objects.

According to Kahneman et al. (1992), the process of object file creation and review consists of several stages. When a visual scene is initially encountered, elements within the scene are parsed into distinct objects. Parsing may be based on grouping principles such as the similarity or proximity of scene elements. There is much evidence to suggest that the segregation of objects in a scene 
occurs without focal attention (see, e.g., Treisman \& Gelade, 1980; Wolfe, 1992). According to Treisman (1988), this stage involves establishing a set of "feature maps" that code perceptual features such as color or orientation, as well as a master map of locations within the scene. The location map indicates the locations of feature boundaries within the scene but does not contain information about which features are present at those locations. Separate feature maps specify the features that are present at each location within the display. When attention is directed to a position within the master location map, all the features at that location are automatically activated. These features are combined, or integrated, to form distinct objects, which are then represented by object files. The object files at this time might include the information that was contained in the feature maps, such as color, shape, and orientation. The file does not contain location information; rather, spatial location is used to address the file. After the file has been created, additional information may be added. The contents of the object file may be compared with a recognition network, which contains descriptions of objects, along with their identities. If the identity of the object can be determined, then it is added to the object file.

On this account, object continuity is maintained through a process that consists of three operations: correspondence, reviewing, and impletion. When a change occurs in the scene, correspondence operations determine whether a new object has appeared, or whether a previous object has changed position. This determination is based on low-frequency spatiotemporal information; features such as shape, color, or identity are irrelevant to the correspondence problem (Kahneman et al., 1992). If no correspondence is found between successive scenes, the object at the new location is seen as novel. If there is correspondence, it is seen as a previously viewed object in a new location. At this point, a reviewing operation retrieves the contents of the previous file for that object and compares it with the characteristics of the object in the current scene. If there is a match, object continuity holds. If the appearance of the object in the current scene is inconsistent with the previous object file contents, however, the object file must either be modified, or discarded and replaced with a new object file. Both of these processes require time; hence, identification of the new object is slowed. Finally, impletion operations establish a link between previous and current object files by creating the appearance of change or motion in the scene.

Kahneman et al. (1992) studied object file effects using a letter identification task. In one experiment, subjects viewed an initial display consisting of two frames, one centered above fixation and the other centered below fixation. A letter was presented within each frame; then both letters were removed, and the frames moved to new positions within the display. One frame moved to the left of fixation, and the other moved to the right of fixation. A single target letter was presented in one of the two frames, and the subjects' task was to name the target letter.
There were three possible relationships between the target and preview letters. In the same-object (SO) condition, the target letter was the same as the preview letter that had been presented within the same frame. In the differentobject (DO) condition, the target letter was the same as the preview letter that had been presented in the other frame. In the no-match (NM) condition, the target letter was different from either preview letter. The authors were interested in the effects of these different preview conditions. They distinguished between two different types of preview effects. Nonspecific preview effects are defined as the difference in response time (RT) between the DO and NM conditions. This effect represents the benefit (or cost) derived from previewing the target letter. If previewing a letter activates the long-term representation of that letter, then identification of the target letter should be facilitated in the SO and DO conditions, relative to the NM condition. The other possible preview effects are object specific. Object-specific effects are the benefits (or costs) derived from previewing a letter within the same frame, or object, in both displays. These effects are defined as the RT difference between the SO and DO conditions. According to object file theory, when a correspondence is found between successive displays, a reviewing procedure compares current objects with the contents of previous object files. When there is a match, as there is in the SO condition, object identification is facilitated. When there is not a match, as in the DO condition, object identification is slowed.

Kahneman et al. (1992) reported significant objectspecific preview effects for the experiment described above. Naming latencies were longer when the target letter was a repetition of the preview letter from the opposite frame (DO) than when it was a repetition of the preview letter in the same frame (SO). This result lends support to object file theory, and it suggests that object identity may be included in an object file. Kahneman et al. also reported nonspecific preview benefits in many of their experiments, although these effects were generally weaker than object-specific effects.

Other researchers have used this basic procedure to argue for the exclusion of certain object characteristics from object files. For example, Henderson (1994) changed the type font of a single letter between successive displays and found that the change did not eliminate object-specific effects. This suggests that information about exact physical form may not be included in an object file.

What information, then, is included in an object file? Current evidence suggests that object files include some perceptual features and also include object identity, if that is known (Henderson, 1994; Henderson \& Anes, 1994; Kahneman et al., 1992). Kahneman et al. (1992) have suggested that object files contain "all the information that defines and describes a particular perceived object" (p. 215), including semantic information and information about appropriate responses. Why, then, is type font not included in an object file? The answer may be that type font can be included in an object file, but it is not in- 
cluded if it is not a defining characteristic of the object. Object identity, on the other hand, is clearly an essential part of any object; as a result, it is typically included in an object file.

\section{THE PRESENT STUDY}

Kahneman et al. (1992) used letters as stimuli. However, one needs to use more complex stimuli in order to test for the presence of a range of information in object files. In the present study, we first attempted to replicate their results - that identity information is stored in object files-using words as stimuli. We then conducted additional experiments to determine whether semantic information is also stored in object files.

Why might one expect object files to contain semantic information about the objects that they represent? One reason is that the inclusion of such information is suggested by the framework of object file theory. Once an object file is created, a long-term recognition network is accessed to determine the object's identity, which can then be included in the file. If the node for that object within the network is activated, the nodes for related objects may also be activated. If so, it is possible that those objects too will be included in the object file. Even if the identities of related objects are not included in object files, one might expect that semantic features or category information might be included. In fact, Henderson (1994) posits a model of object file creation that explicitly includes a mechanism whereby semantic category information is included in object files, and he argues that any information about the object that is retrieved from longterm memory is a candidate for inclusion in the object file.

If it is true, as Henderson (1994) and Kahneman et al. (1992) have argued, that object files may include any information that is retrieved from long-term memory, then the hypothesis that object files contain semantic information hinges on the assumption that object recognition activates semantic information in long-term memory. There is much evidence to support this assumption, in experiments using both lexical and pictorial stimuli. For example, many researchers have demonstrated that the naming or classification of a word is facilitated by preview of a related word (e.g., Balota \& Lorch, 1986; Meyer \& Schvaneveldt, 1971). Furthermore, there is some evidence that the activation of semantic information is an automatic consequence of word recognition (cf. Lesch \& Pollatsek, 1993). In fact, Underwood (1976) has argued that the meaning of a word is available preattentively. The evidence of semantic priming and of automatic semantic activation support the assumption that semantic information is available to be included in object files.

In sum, in Experiments 1-3, we investigated whether lexical identity is included in an object file that represents a word. In Experiment 4, we used a semantic priming task to determine whether such an object file also includes the identities of related items. In Experiment 5, we used synonyms as prime-target pairs to investigate whether the semantic features of an object are included in its object file. Finally, in Experiment 6, we tested whether information about the category to which an object belongs is stored in its object file.

\section{EXPERIMENT 1}

In the first experiment, we investigated whether lexical identity is stored in an object file. To test this, a lexical priming paradigm was used with a lexical decision task. Subjects viewed an initial display consisting of two preview words, one located above fixation and the other located below fixation. Each word was displayed within a rectangular frame. The words disappeared; then, a short time later, a single word or nonword target was displayed inside one of the frames. In the SO condition, the target was a repetition of one of the preview words, presented inside of the frame in which it had previously appeared. In the DO condition, the target was a repetition of one of the preview words, presented inside of the frame opposite the one in which it had previously appeared. In the NM condition, the target was a novel word. From this design, a distinction can be made between two types of preview benefits. A nonspecific preview benefit is the advantage in lexical decision time that results from previewing the target stimulus. Consistent with Kahneman et al. (1992), we calculate this benefit as the difference between the NM and DO conditions. An object-specific preview benefit, on the other hand, is the advantage in lexical decision time that results from viewing the target stimulus within the same object in the preview and target displays. Object-specific preview effects, the RT difference between the SO and DO conditions, are of primary importance to the issue of the contents of an object file; if a significant object-specific preview benefit for lexical identity is found, that is evidence that lexical identity is included in an object file.

\section{Method}

Subjects. Twenty-four subjects participated in this experiment for course credit. All were undergraduate students at the University of Illinois at Urbana-Champaign who were naive about the purpose of the experiment. All subjects had either normal or corrected-tonormal vision and were native English speakers.

Stimuli. The stimuli consisted of 352 words and 72 nonwords Twelve of the words were used as target items in the practice block, and 60 of the words were used as targets in the experimental block; preview items in the practice and experimental blocks were drawn from the 280 words that remained. Within a given experimental block, 200 words were used as preview items for the word and nonword trials; in the practice block, 40 words were used as preview items. The remainder of the preview items used were repetitions of target items. Each subject saw every target word exactly once. The words varied in length from three to eight letters. The preview words had a mean written frequency of 160 per million $(S D=156)$, and the targets had a mean frequency of 183 per million $(S D=316)$ (Francis \& Kučera, 1982). The words used are listed in Appendix A. The nonwords were taken from a set of legal nonwords published by Sereno (1991), and they followed standard English rules of orthography and pronunciation. The nonwords used are listed in Appendix D. Each item was surrounded in the display by a rectangu- 
lar frame, which was intended to emphasize the existence of two unique objects within the display, and to provide spatiotemporal continuity between the preview and target displays.

Apparatus. The stimuli were presented on an NEC MultiSync 3FGx color monitor equipped with a monitor lens to reduce reflectance. The monitor had a refresh rate of $72 \mathrm{~Hz}$. Stimulus presentation was controlled with a Gateway $200048650-\mathrm{MHz}$ computer with an SVGA graphics adapter. During the experiment, subjects were seated approximately $57 \mathrm{~cm}$ from the monitor screen. At this distance, the total display area subtended a visual angle of $26^{\circ}$ horizontally and $19.7^{\circ}$ vertically. The size of the stimuli ranged from $1^{\circ}$ (for three-letter words) to $2.8^{\circ}$ (for nine-letter words) horizontally. The height of each word was $0.6^{\circ}$ of visual angle. The rectangular frame that surrounded each item subtended a visual angle of $3.2^{\circ}$ horizontally and $1.2^{\circ}$ vertically. Each stimulus item was centered within the rectangular frame. At the center of the display was a fixation cross which measured $0.5^{\circ}$ high and $0.3^{\circ}$ wide. One frame was located above the fixation cross, and the other was located below the fixation cross. The vertical distance from the center of the fixation cross to the center of each frame was $2.4^{\circ}$ (in other words, the edge-to-edge separation of the frames was $3.6^{\circ}$ ).

The stimuli were presented in $640 \times 200$ graphics mode, using a font which presents characters in an $8 \times 8$ grid. The display background was white (luminance $=66 \mathrm{~cd} / \mathrm{m}^{2}$ ), and the stimuli, frames, and fixation cross were drawn in dark gray (luminance $=14 \mathrm{~cd} / \mathrm{m}^{2}$ ). The stimuli were written entirely in lowercase.

The subjects responded by pressing one of two microswitches that were held in either hand and connected to the computer via a digital input board.
Procedure. Figure 1 shows examples of displays used in Experiment 1 . The subjects began each trial by fixating a small cross at the center of the screen, then depressing both switches at once. The rectangular frames were displayed for $500 \mathrm{msec}$; then one word appeared within each frame. The words remained visible for $1.5 \mathrm{sec}$; then they disappeared. The empty frames were displayed for an interstimulus interval of $250 \mathrm{msec}$; then a single word or nonword target was presented until the subject made a response. The subjects pressed the switch in their left hand if the target item was a nonword, and pressed the switch in their right hand if the target was a word. Lexical decision time was measured from the onset of the target display until one of the microswitches was pressed. The fixation cross and the rectangular frames were visible throughout the trial.

In this experiment and those that follow, subjects completed one block of 24 practice trials and one block of 120 experimental trials. In half of all the trials, the target was a nonword. Of particular interest were the trials in which the target was a word. These trials can be divided into three classes: SO, DO, and NM. In the SO trials, the target was a repetition of the preview item that had appeared within the same frame. In the DO trials, the target was a repetition of the preview item that had appeared in the other frame. In the NM condition, the item was a novel word.

Across subjects, each target item appeared equally often in each location (top or bottom frame) and in each condition (SO, DO, or NM). To achieve this counterbalanced design, six stimulus lists were created; the trial characteristics for each subject were specified by one of the lists. For this experiment, 4 subjects saw each of the lists. Within each list, each item occurred only once. The target items were the same in every list. The preview items and target lo-

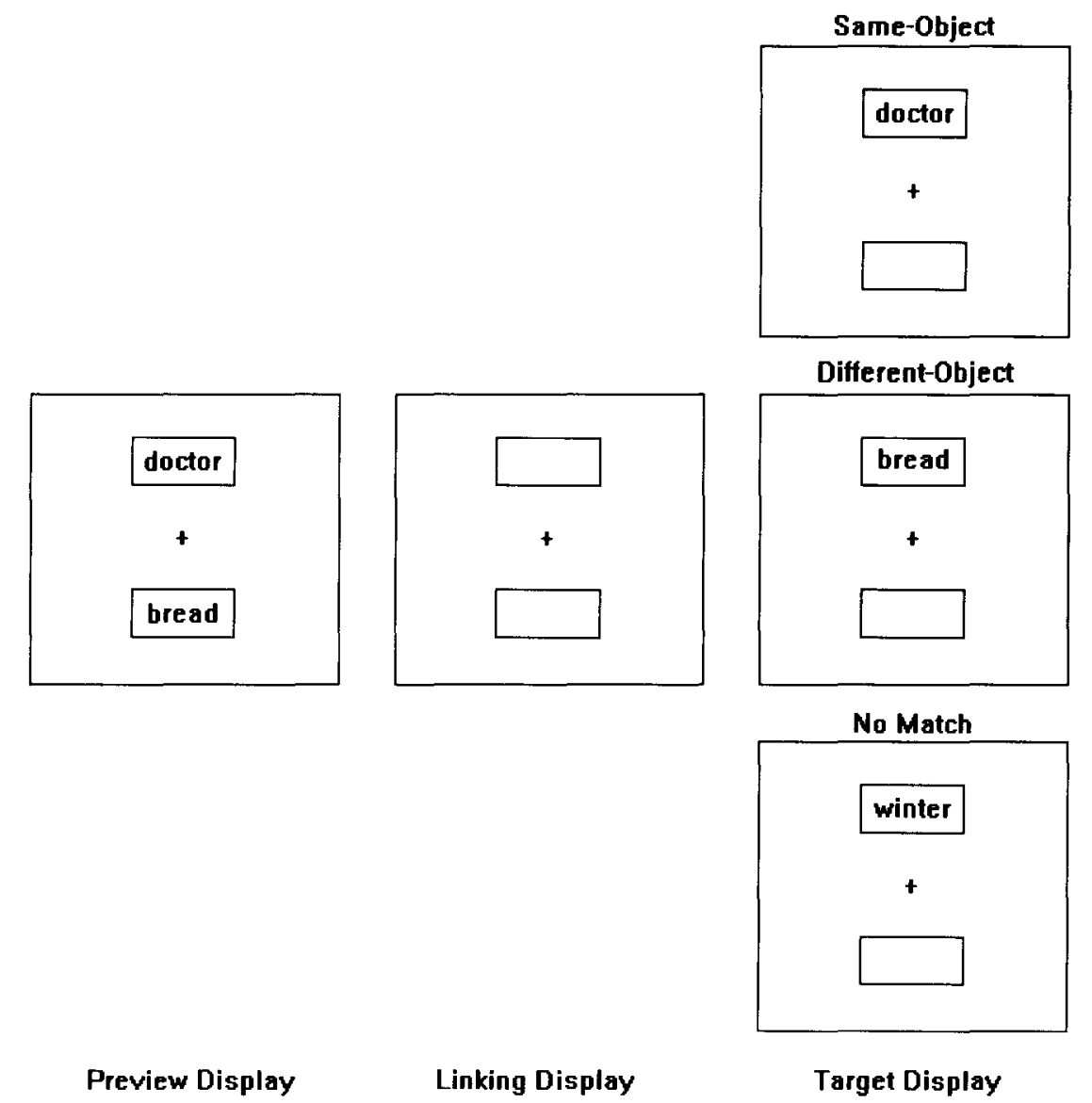

Figure 1. Example of displays used in Experiment 1 (not drawn to scale). 
cation were varied across lists to change the condition in which the target occurred. Before analyzing the data, we eliminated trials in which a subject's RT differed by more than $2.5 S D$ s from his/her mean RT in that condition.

Because each target word appeared in each condition across subjects, we are able to report the results of separate analyses which treated subjects $\left(F_{1}\right)$ and items $\left(F_{2}\right)$ as random factors.

\section{Results}

Table 1 presents the mean RTs for correct trials and error rates in each of the three conditions of interest, for each possible target location. The analysis excludes the $1.0 \%$ of the trials that did not meet our criterion (described in the Method section). Repeated measures analyses of variance (ANOVAs) were performed on both RT data and error data.

The results of the RT ANOVA indicated a significant effect of condition, with mean RTs of 606,639 , and $718 \mathrm{msec}$ in the SO, DO, and NM conditions, respectively $\left[F_{1}(2,46)=54.3, M S_{\mathrm{e}}=2,903, p<.001 ; F_{2}(2,118)=\right.$ $\left.59.5, M S_{\mathrm{e}}=7,171, p<.001\right]$. Subjects also responded more quickly when the target appeared in the top frame (mean RT $=617 \mathrm{msec}$ ) than when it appeared in the bottom frame $($ mean RT $=691 \mathrm{msec})\left[F_{1}(1,23)=21.0\right.$, $M S_{\mathrm{e}}=9,259, p<.001 ; F_{2}(1,59)=76.3, M S_{\mathrm{e}}=7,021$, $p<.001]$. This result may reflect a bias for attention to be allocated to the top of a display, a bias that probably results from reading patterns. There was no significant interaction of condition and location $\left[F_{1}(2,46)=2.2, M S_{\mathrm{e}}=\right.$ $\left.2,195, p>.10 ; F_{2}(2,118)=1.7, M S_{\mathrm{e}}=7,112, p>.10\right]$.

The effects of primary interest in the present investigation were the nonspecific preview effect and the objectspecific preview effect. The nonspecific preview effect is defined by Kahneman et al. (1992) as the RT difference between the NM condition and the DO condition. This measures the benefit of previewing the target item, regardless of whether it maintains object continuity. Planned comparisons were performed to investigate the nature of these effects. In the present experiment, there was a significant nonspecific preview effect; subjects responded more slowly to a novel word (mean RT $=718 \mathrm{msec}$ ) than to a word that had been previously viewed in a different frame (mean RT $=639 \mathrm{msec})\left[F_{1}(1,23)=50.5, M S_{\mathrm{e}}=\right.$ $2,903, p<.001 ; F_{2}(1,59)=52.3, M S_{\mathrm{e}}=7,171, p<$ $.001]$. This suggests that subjects benefited from previewing the target item.

\section{Table 1}

Mean Response Times (RT) and Preview Effects (in Milliseconds), With Error Rates, in Experiment 1

\begin{tabular}{|c|c|c|c|c|c|c|}
\hline \multirow[b]{3}{*}{ Condition } & \multicolumn{6}{|c|}{ Target Location } \\
\hline & \multicolumn{2}{|c|}{ Top } & \multicolumn{2}{|c|}{ Bottom } & \multicolumn{2}{|c|}{ Overall } \\
\hline & RT & $\% \mathrm{E}$ & RT & $\% \mathrm{E}$ & RT & $\% \mathrm{E}$ \\
\hline Same object & 580 & 1.7 & 631 & 1.7 & 606 & 1.7 \\
\hline Different object & 594 & 2.5 & 684 & 3.3 & 639 & 2.9 \\
\hline No match & 678 & 5.0 & 757 & 6.7 & 718 & 5.9 \\
\hline$M$ & 617 & 3.1 & 691 & 3.9 & 654 & 3.5 \\
\hline \multicolumn{7}{|c|}{ Preview Effects } \\
\hline Object specific & 14 & 0.8 & 53 & 1.6 & 33 & 1.2 \\
\hline Nonspecific & 84 & 2.5 & 73 & 3.4 & 79 & 3.0 \\
\hline
\end{tabular}

If lexical identity is included in the object files that represent the preview items, there should be an additional benefit of previewing the target item within the same frame. In fact, this was found to be the case. Planned comparisons indicated that subjects responded more quickly to a target that had been previewed within the same frame (mean RT $=606 \mathrm{msec}$ ) than to a target that had been previewed within a different frame (mean $\mathrm{RT}=639 \mathrm{msec}$ ) $\left[F_{1}(1,23)=9.3, M S_{\mathrm{e}}=2,903, p<.01 ; F_{2}(1,59)=11.9\right.$, $\left.M S_{\mathrm{e}}=7,171, p<.01\right]$.

The ANOVA performed on the error rates showed evidence of a significant effect of condition, with mean error rates of $1.7 \%, 2.9 \%$, and $5.9 \%$ in the $\mathrm{SO}, \mathrm{DO}$, and NM conditions, respectively $\left[F_{1}(2,46)=4.7, M S_{\mathrm{e}}=0.005\right.$, $\left.p<.025 ; F_{2}(2,118)=7.1, M S_{\mathrm{e}}=0.008, p<.005\right]$, but no effect of location $\left[F_{1}(1,23)<1, M S_{\mathrm{e}}=0.003 ; F_{2}(1,59)\right.$ $\left.=1.1, M S_{\mathrm{e}}=0.006, p>.20\right]$. There was no interaction of condition with location $\left[F_{1}(2,46)<1, M S_{\mathrm{e}}=0.003\right.$; $\left.F_{2}(2,118)<1, M S_{\mathrm{e}}=0.008\right]$. There was a marginally significant nonspecific preview benefit; subjects tended to be more accurate when they had previewed the target in a different frame (mean error rate $=2.9 \%$ ) than when the target was a novel stimulus (mean error rate $=5.9 \%$ ) $\left[F_{1}(1,23)=4.2, M S_{\mathrm{e}}=0.005, p=.06 ; F_{2}(1,59)=6.5\right.$, $\left.M S_{\mathrm{e}}=0.008, p<.025\right]$. However, there was no objectspecific preview effect on error rates $\left[F_{1}(1,23)<1, M S_{\mathrm{e}}=\right.$ $\left.0.005 ; F_{2}(1,59)=1.1, M S_{\mathrm{e}}=0.008, p>.20\right]$.

\section{Discussion}

The results of Experiment 1 offer clear support for the hypothesis that object identity is included in a newly constructed object file. In the preview display, subjects observed two distinct objects, the stimuli surrounded by frames. As attention was directed to each item, a separate object file was constructed to represent each item. In the target display, subjects observed a stimulus item that was either consistent or inconsistent with the item that had previously appeared in that position. A comparison was made between the current contents of the object file and its most recent occurrence. When they were consistent, as in the SO trials, a response could be made immediately. If, on the other hand, they were inconsistent, the existing object file was either radically modified or discarded altogether. As a result, RTs were faster in the SO condition than in the DO condition. The RT difference reflects the time required to construct a new object file or modify an existing file.

From the results reported above, it is not clear whether object identity is bound to particular objects, or whether it is instead bound to particular spatial locations. In Experiment 1 , the objects remained fixed in space, so either (perhaps both) interpretation might be correct. In Experiment 2 , we attempted to separate them by using stimuli that were not location bound.

\section{EXPERIMENT 2}

In Experiment 2, the frames in which the stimuli appeared were not fixed to one location within the display. 
Instead, they moved to new positions following the preview display. It was expected that this would address the issue of whether the difference between the SO and DO conditions in Experiment 1 really was an object-specific effect, or whether it could be more accurately labeled a location-specific effect. In other words, the benefit derived from previewing a stimulus within the same frame might be due to the inclusion of identity information within an object file, but it might also be due to an advantage of stimuli that remained in a fixed location. In the present experiment, stimuli never remained in a fixed location. If object-specific preview effects should be found, therefore, they could be attributed to the inclusion of object identity within an object file.

\section{Method}

Subjects. Twenty-four subjects each received $\$ 5$ as payment for their participation.

Stimuli. The stimuli were the same as in Experiment 1.

Apparatus. The apparatus was the same as in Experiment 1. Apparent motion of the frames was achieved by displaying 15 successive graphics pages. On each page, the frames were displaced by approximately $0.2^{\circ}$ relative to the previous page. Each page was displayed for $14 \mathrm{msec}$. In the target display, the frames were presented to either side of the central fixation cross. The horizontal distance from the center of fixation to the center of each frame was $2.4^{\circ}$ (the edge-to-edge separation of the frames in the target display was therefore $1.6^{\circ}$ ). On half of the trials, the frames appeared to move clockwise around the cross, and on the other half, the movement was counterclockwise. The path of movement was a straight line from the initial (preview) position to the final (target) position, as depicted in Figure 2. The total displacement of each frame on every trial was $3.4^{\circ}$.

Procedure. Figure 2 shows examples of displays used in Experiment 2 . Subjects initiated the trial by pressing both microswitches at once. A display consisting of empty frames above and below a fixation cross was presented for $500 \mathrm{msec}$, followed by presentation of a stimulus item within each frame for $1.5 \mathrm{sec}$. The stimuli disappeared; then the frames appeared to move either clockwise or counterclockwise until they were on either side of the fixation cross. The total time of this motion was $210 \mathrm{msec}$. After the boxes stopped moving, a target stimulus was presented within one of the frames, and it remained present until a response was made.

Clockwise and counterclockwise movement occurred on an equal number of trials. Movement direction was randomized within the experimental block. As in Experiment 1, counterbalancing was achieved by preparing six stimulus lists, so that each target appeared in each location and condition. As a result, 4 subjects saw each list.

\section{Results}

The mean RTs for correct trials and error rates for Experiment 2 are presented in Table 2 . These means exclude the $0.8 \%$ of the trials that failed to meet our crite-
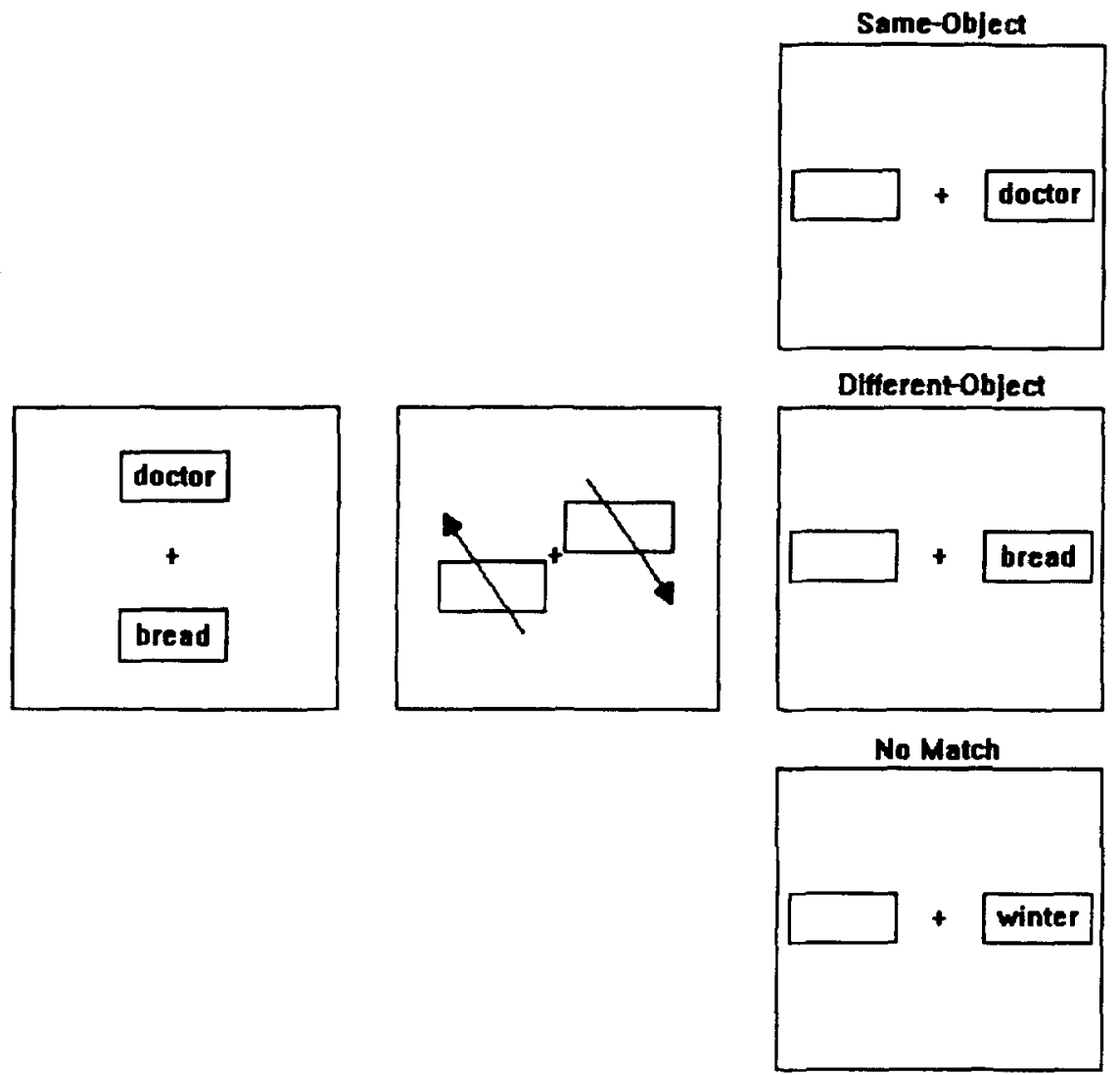
rion. Repeated measures ANOVAs were performed on the RT and error rate data.

The results of the RT ANOVA indicate a significant effect of condition, with mean RTs of 635,656 , and $721 \mathrm{msec}$ for the SO, DO, and NM conditions, respectively $\left[F_{1}(2,46)=35.5, M S_{\mathrm{e}}=2,703, p<.001 ; F_{2}(2,118)\right.$ $\left.=19.1, M S_{\mathrm{e}}=11,499, p<.001\right]$. There was no main effect of target location $\left[F_{1}(1,23)=1.9, M S_{\mathrm{e}}=4,794, p>\right.$ $\left..10 ; F_{2}(1,59)=2.4, M S_{\mathrm{e}}=18,414, p>.10\right]$, and there was no interaction of condition and location $\left[F_{1}(2,46)=\right.$ $2.0, M S_{\mathrm{e}}=4,262, p>.10 ; F_{2}(2,118)=1.1, M S_{\mathrm{e}}=$ $10,162, p>.10]$. In this experiment, location refers not to the location of the target stimulus within the target display, but to the position of the target frame within the preview display. In other words, "top" means that the target word appeared within the frame that had been at the top of the preview display; "bottom" means that the target frame had been at the bottom of the preview display.

As in Experiment 1, there was evidence of nonspecific preview effects on RT. Planned comparisons indicated that subjects responded more quickly when the target was a repetition of the DO preview item (mean RT $=656 \mathrm{msec}$ ) than when it was a novel word (mean RT $=721 \mathrm{msec}$ ) $\left[F_{1}(1,23)=37.2, M S_{\mathrm{e}}=2,703, p<.001 ; F_{2}(1,59)=21.9\right.$, $\left.M S_{\mathrm{e}}=11,499, p<.001\right]$. This suggests that subjects benefited from previewing the target item. However, the objectspecific effect was only marginally significant $\left[F_{1}(1,23)=\right.$ $4.0, M S_{\mathrm{e}}=2,703, p=.065 ; F_{2}(1,59)=1.3, M S_{\mathrm{e}}=$ $11,499, p>.10]$.

The ANOVA performed on the error rates showed no effect of condition $\left[F_{1}(2,46)<1, M S_{\mathrm{e}}=0.005 ; F_{2}(2,118)\right.$ $\left.<1, M S_{\mathrm{e}}=0.015\right]$ or of location $\left[F_{1}(1,23)<1, M S_{\mathrm{e}}=\right.$ $\left.0.004, F_{2}(1,59)<1, M S_{\mathrm{e}}=0.011\right]$. There was no interaction of condition with location $\left[F_{1}(2,46)<1, M S_{\mathrm{e}}=\right.$ $\left.0.004 ; F_{2}(2,118)<1, M S_{\mathrm{e}}=0.011\right]$.

\section{Discussion}

In Experiment 1, objects were stationary throughout the trial; as a result, the object-specific preview benefits that were observed could not be separated from locationspecific preview benefits. In the present experiment, the objects changed position between the preview and target display; as a result, any object-specific benefits can be attributed to the fact that the preview and target were pre-

Table 2

Mean Response Times (RT) and Preview Effects (in Milliseconds), With Error Rates, in Experiment 2

\begin{tabular}{|c|c|c|c|c|c|c|}
\hline \multirow[b]{3}{*}{ Condition } & \multicolumn{6}{|c|}{ Target Location } \\
\hline & \multicolumn{2}{|c|}{ Top } & \multicolumn{2}{|c|}{ Bottom } & \multicolumn{2}{|c|}{ Overall } \\
\hline & RT & $\% \mathrm{E}$ & RT & $\% \mathrm{E}$ & RT & $\% \mathrm{E}$ \\
\hline Same object & 644 & 2.5 & 627 & 5.4 & 635 & 4.0 \\
\hline Different object & 677 & 4.6 & 635 & 4.2 & 656 & 4.4 \\
\hline No match & 716 & 5.0 & 727 & 5.0 & 721 & 5.0 \\
\hline$M$ & 679 & 4.0 & 663 & 4.9 & 671 & 4.5 \\
\hline \multicolumn{7}{|c|}{ Preview Effects } \\
\hline Object specific & 33 & 2.1 & 8 & -1.2 & 21 & 0.4 \\
\hline Nonspecific & 39 & 0.4 & 92 & 0.8 & 65 & 0.6 \\
\hline
\end{tabular}

sented within the same object. The results did not indicate a clear object-specific effect. However, there was a strong trend in the direction which would be predicted if object identity was included within object files. The reason that the effect was not statistically significant in this experiment may be that the effect was smaller in this case. In Experiment 1, the observed benefits may have reflected both object-specific and location-specific preview benefits. In the present experiment, the location-specific benefits were removed; what remained was the objectspecific benefit, which, though present, was somewhat weaker than the combined benefit of location and object invariance.

Another possible explanation for the fact that the objectspecific effects in Experiment 2 were only marginally significant is that the nature of the linking display required the subjects to engage in additional processing. In Experiment 1 , the objects remained fixed during the linking display; in Experiment 2, the objects changed location. This required the subjects to track each object as it moved. Evidence suggests that object tracking involves short-term memory processes (Pylyshyn, 1989). Given that object files are maintained within short-term memory, it is possible the increase in short-term memory load demanded by the tracking task reduced the number of object files that could be maintained. In other words, subjects may not have been able to maintain both object files throughout the experiment; this would have weakened the object-specific effect. This argument suggests that reducing short-term memory load should increase object-specific effects. In fact, this is consistent with a result reported by Kahneman et al. (1992). Following the display, they provided subjects with a precue that indicated the object in which the target would be presented. This should presumably decrease short-term memory load, because subjects need track only one object during the linking display. The results indicated that providing subjects with a precue more than doubled the observed objectspecific effect. This is consistent with the argument that the results of the present experiment were weakened by the tracking task.

\section{EXPERIMENT 3}

The results of Experiments 1 and 2 are generally consistent with the argument that object files maintain an abstract identity code for the objects that they represent. However, an alternative explanation is that object files contain a detailed physical code for the objects that they represent, rather than an identity code. Because the sameidentity stimuli in the previous experiments were physically identical, the results were consistent with either explanation. In order to disentangle the benefits of maintaining the same identity code from the benefits of maintaining the same physical code, in Experiment 3 we manipulated the physical appearance of the preview and target words by changing the case in which they were printed. If object files contain an abstract code for identity, then changing the physical form of the word should not 
eliminate the object-specific preview benefit. However, if the object- or location-specific benefit observed in Experiments 1 and 2 was due to the storage of a detailed physical code for the object, the benefit should be reduced or eliminated when the physical appearance of the object changes.

\section{Method}

Subjects. Seventy-two subjects participated for course credit.

Stimuli. The stimuli were the same as in Experiment 1, except that we varied the case in which the words were written.

Apparatus. The apparatus was the same as in Experiment 1.

Procedure. The procedure was identical to that used in Experiment 1 , except that we manipulated the case in which preview and target items were printed. In half of the trials in which the target had the same name as one of the preview words, the target and its samename preview word were printed in the same (either upper or lower) case; in the remaining trials, the word was printed in lowercase in one display and uppercase in the other display. In half of the samecase trials, both the target and its same-name preview word were printed in lowercase; in the other half of the same-case trials, both were printed in uppercase. In half of the different-case trials, the samename preview was printed in lowercase and the target was printed in uppercase; this was reversed in the remaining half of the differentcase trials. In all trials, one of the preview words was printed in uppercase and the other preview word was printed in lowercase. Between subjects, each target occurred equally often in each condition. To achieve this counterbalanced design, we created 24 stimulus lists ( 2 locations $\times 3$ conditions $\times 2$ preview cases $\times 2$ target cases); each list was presented to 3 subjects.

\section{Results}

Table 3 presents the mean RTs for correct trials and error rates in each of the three conditions of interest, for each possible target location and case type (same/different). These means exclude trials in which a subject's RT differed by more than $1.75 S D$ s from his/her mean RT in that condition. This criterion resulted in the exclusion of

Table 3

Mean Response Times (RT) and Preview Effects (in Milliseconds), With Error Rates, in Experiment 3

\begin{tabular}{|c|c|c|c|c|c|c|}
\hline \multirow[b]{3}{*}{ Condition } & \multicolumn{6}{|c|}{ Target Location } \\
\hline & \multicolumn{2}{|c|}{ Top } & \multicolumn{2}{|c|}{ Bottom } & \multicolumn{2}{|c|}{ Overall } \\
\hline & RT & $\% \mathrm{E}$ & $\mathrm{RT}$ & $\% \mathrm{E}$ & RT & $\% \mathrm{E}$ \\
\hline \multicolumn{7}{|c|}{ Same Case } \\
\hline Same object & 563 & 0.6 & 632 & 1.4 & 598 & 1.0 \\
\hline Different object & 578 & 2.5 & 648 & 2.5 & 613 & 2.5 \\
\hline No match & 665 & 3.9 & 741 & 5.6 & 703 & 4.8 \\
\hline$M$ & 602 & 2.3 & 674 & 3.2 & 638 & 2.8 \\
\hline \multicolumn{7}{|c|}{ Preview Effects } \\
\hline Object specific & 15 & 1.9 & 16 & 1.1 & 15 & 1.5 \\
\hline Nonspecific & 87 & 1.4 & 93 & 3.1 & 90 & 2.3 \\
\hline \multicolumn{7}{|c|}{ Different Case } \\
\hline Same object & 588 & 1.4 & 643 & 2.2 & 616 & 1.8 \\
\hline Different object & 588 & 1.7 & 681 & 3.1 & 635 & 2.4 \\
\hline No match & 642 & 2.2 & 762 & 4.7 & 702 & 3.5 \\
\hline$M$ & 606 & 1.8 & 695 & 3.3 & 651 & 2.6 \\
\hline \multicolumn{7}{|c|}{ Preview Effects } \\
\hline Object specific & 0 & 0.3 & 38 & 0.9 & 19 & 0.6 \\
\hline Nonspecific & 54 & 0.5 & 81 & 1.6 & 67 & 1.1 \\
\hline
\end{tabular}

$0.9 \%$ of the trials. The criterion differed from that used in the other experiments reported here because there were fewer trials per condition for each subject. Repeated measures ANOVAs were performed on both RT data and error data.

The results of the response time ANOVA indicate a significant effect of condition, with mean RTs of 607, 624, and $703 \mathrm{msec}$ in the SO, DO, and NM conditions, respectively $\left[F_{1}(2,142)=138.5, M S_{\mathrm{e}}=5,450, p<.001\right.$; $\left.F_{2}(2,118)=96.5, M S_{\mathrm{e}}=6,311, p<.001\right]$. There was also a main effect of location; subjects responded more quickly when the target appeared in the top frame (mean $\mathrm{RT}=604 \mathrm{msec}$ ) than when it appeared in the bottom frame (mean RT $=685 \mathrm{msec})\left[F_{1}(1,71)=100.5, M S_{\mathrm{e}}=\right.$ $13,995, p<.001 ; F_{2}(1,59)=256.6, M S_{\mathrm{e}}=4,939, p<$ $.001]$. Subjects also responded more quickly when the target and same-name preview were written in the same case (mean RT $=638 \mathrm{msec}$ ) than when they were written in a different case $($ mean $\mathrm{RT}=651 \mathrm{msec})[F(1,71)=$ $\left.6.0, M S_{\mathrm{e}}=5,776, p<.05\right]$, although this was not significant by items $\left[F_{2}(1,59)=3.3, M S_{\mathrm{e}}=4,999, p>.05\right]$. There was a significant condition $\times$ location interaction $\left[F_{1}(2,142)=3.4, M S_{\mathrm{e}}=6,950, p<.05 ; F_{2}(2,118)=\right.$ $\left.3.4, M S_{\mathrm{e}}=4,743, p<.05\right]$; object-specific benefits and nonspecific benefits were larger for the bottom location than for the top location. There was no interaction of location and case $\left[F_{1}(1,71)=2.3, M S_{\mathrm{e}}=7,610, p>.10\right.$; $\left.F_{2}(1,59)=1.3, M S_{\mathrm{e}}=4,747, p>.10\right]$. The case $\times$ condition interaction was significant by items $\left[F_{2}(2,118)=\right.$ $\left.3.2, M S_{\mathrm{e}}=4,483, p<.05\right]$, but not by subjects $\left[F_{1}(2,142)\right.$ $\left.=1.4, M S_{\mathrm{e}}=7,668, p>.10\right]$. The nature of this interaction is described below. There was also no interaction of all three variables $\left[F_{1}(2,142)=2.5, M S_{\mathrm{e}}=6,039, p>\right.$ $\left..05 ; F_{2}(2,118)=1.7, M S_{\mathrm{e}}=5,158, p>.10\right]$. This result is important, because it suggests that the preview benefits obtained in Experiment 3 were not affected by changes in the physical form of the stimuli.

We were most interested in calculating the objectspecific and nonspecific preview effects and in determining how they were affected by changes in physical form. In Experiment 3, there was a significant nonspecific preview effect; subjects responded more slowly to a novel word (mean RT $=703 \mathrm{msec}$ ) than to a word that had been viewed previously in a different frame (mean $\mathrm{RT}=$ $624 \mathrm{msec})\left[F_{1}(1,71)=164.7, M S_{\mathrm{e}}=5,450, p<.001\right.$; $\left.F_{2}(1,59)=138.1, M S_{e}=6,311, p<.001\right]$. This suggests that subjects benefited from previewing the target item. This nonspecific benefit did not interact with case $\left[F_{1}(1,71)\right.$ $\left.=2.4, M S_{\mathrm{e}}=7,668, p>.10\right]$, except in the items analyses $\left[F_{2}(1,59)=6.2, M S_{\mathrm{e}}=4,483, p<.025\right]$. This interaction is apparently the main component of the condition $X$ case interaction reported previously. The nonspecific effect was larger in the same-case condition $(90 \mathrm{msec})$ than in the different-case condition $(67 \mathrm{msec})$, though both were significant.

In addition to nonspecific benefits, we also found evidence of object-specific preview benefits. Planned comparisons indicated that subjects responded more quickly to a target that had been previewed within the same frame 
(mean RT $=607 \mathrm{msec}$ ) than to a target that had been previewed within a different frame (mean $\mathrm{RT}=624 \mathrm{msec}$ ) $\left[F_{1}(1,71)=7.6, M S_{\mathrm{e}}=5,450, p<.01 ; F_{2}(1,59)=6.2\right.$, $\left.M S_{\mathrm{e}}=6,311, p<.025\right]$. As with the nonspecific benefit, the object-specific benefit did not interact with case $\left[F_{1}(1,71)<1, M S_{\mathrm{e}}=7,668 ; F_{2}(1,59)<1, M S_{\mathrm{e}}=4,483\right]$. Using the error term for the interaction from the subjects' analysis, the $95 \%$ confidence interval for this comparison was $4 \pm 29 \mathrm{msec}$. This result shows that objectspecific preview benefits persist even when the physical form of the stimulus changes.

The ANOVA performed on the error rates showed evidence of a significant effect of condition, with mean error rates of $1.4 \%, 2.5 \%$, and $4.2 \%$ in the SO, DO, and $\mathrm{NM}$ conditions, respectively $\left[F_{1}(2,142)=8.5, M S_{\mathrm{e}}=\right.$ $0.006, p<.001 ; F_{2}(2,118)=10.6, M S_{\mathrm{e}}=0.004, p<$ .0011 . Subjects were also more accurate when the target appeared in the top frame (mean error rate $=2.1 \%$ ) than when it appeared in the bottom frame (mean error rate $=$ $3.3 \%)\left[F_{1}(1,71)=6.9, M S_{\mathrm{e}}=0.005, p<.05 ; F_{2}(1,59)\right.$ $\left.=5.3, M S_{\mathrm{e}}=0.005, p<.05\right]$. There was no interaction of condition $\times$ location $\left[F_{1}(2,142)<1, M S_{\mathrm{e}}=0.005\right.$; $\left.F_{2}(2,118)<1, M S_{\mathrm{e}}=0.005\right]$, of condition $\times$ case $\left[F_{1}(2,142)=2.3, M S_{\mathrm{e}}=0.003, p>.05 ; F_{2}(2,118)=1.5\right.$, $\left.M S_{\mathrm{e}}=0.004, p>.10\right]$, or of location $\times$ case $\left[F_{1}(1,71)<\right.$ $\left.1, M S_{\mathrm{e}}=0.004 ; F_{2}(1,59)<1, M S_{\mathrm{e}}=0.005\right]$. There was no three-way interaction $\left[F_{1}(2,142)<1, M S_{\mathrm{e}}=0.005\right.$; $\left.F_{2}(2,118)<1, M S_{\mathrm{e}}=0.005\right]$. There was a significant nonspecific preview benefit $\left[F_{1}(1,71)=6.5, M S_{\mathrm{e}}=0.006\right.$, $\left.p<.025 ; F_{2}(1,59)=10.4, M S_{\mathrm{e}}=0.004, p<.01\right]$, which did not interact with case $\left[F_{1}(1,71)=1.7, M S_{\mathrm{e}}=0.003\right.$, $\left.p>.10 ; F_{2}(1,59)=1.1, M S_{\mathrm{e}}=0.004, p>.10\right]$. There was no significant object-specific preview benefit $\left[F_{1}(1,71)\right.$ $=2.6, M S_{\mathrm{e}}=0.006, p>.10 ; F_{2}(1,59)=3.8, M S_{\mathrm{e}}=$ $0.004, p>.05]$.

\section{Discussion}

The results of Experiments 1 and 2 suggested that object identity was included in object files. However, a second possibility was that only a detailed physical description of each preview object was included in its object file. In Experiment 3, we found that changing the physical characteristics of the object between the preview and target displays did not eliminate, or even reduce, the objector location-specific effects. This suggests that object files maintain abstract identity information about the objects that they represent.

\section{EXPERIMENT 4}

In Experiment 4, a semantic priming paradigm was used to determine whether information about items that are semantically related to a presented object is included in its object file. For example, if subjects view the word $d o g$, an object file would be created to include the concept $d o g$. However, it may also include related concepts, such as cat. If this is the case, RTs should be faster if the target word cat is presented within the same object as the preview word $\operatorname{dog}$ than if it is presented within a different object, or if unrelated preview stimuli are presented. Therefore, object-specific preview benefits in Experiment 4 would be evidence of the existence of semantic information within an object file, as suggested by Kahneman et al. (1992).

\section{Method}

Subjects. Twenty-four subjects received $\$ 5$ as payment for their participation.

Stimuli. The stimuli consisted of 420 words and 72 nonwords. The words included the 352 words used in Experiment 1, plus an additional 68 words that were related to the targets used. The additional words allowed us to form 60 related preview-target pairs which were available for the experimental block, and 8 related previewtarget pairs in the practice block (only 8 related pairs were required for the practice block, because only eight of the practice trials were SO or DO trials). These words had been determined to be very closely related in previous research (Balota \& Lorch, 1986; Fischler, 1977; Lupker, 1984; Palermo \& Jenkins, 1964). The mean frequency of the preview words was 147 per million $(S D=172)$, and the mean frequency of the target words was 183 per million $(S D=316)$ (Francis \& Kučera, 1982). Each subject saw every target item exactly once. Across subjects, each target item appeared in every condition and location. To achieve this design, six stimulus lists were created, each of which specified the condition and location for every target item, as well as the preview items for that target. Each list was therefore presented to 4 subjects. For the SO and DO conditions, the preview items consisted of a word that was semantically related to the target and a word that was unrelated to the target and the other preview item. For the NM condition, the preview items were two words that were unrelated to each other and to the target item. The word stimuli are listed in Appendix A.

Apparatus. The apparatus was the same as in Experiment 1.

Procedure. Figure 3 shows examples of displays used in Experiment 4. The procedure was the same as in Experiment 1.

As before, there were three conditions for the word trials. In the SO condition, the target word was related to the preview word that had been displayed in the same frame. In the DO condition, the target word was related to the preview word that had previously been displayed in the other frame. In the NM condition, the target item was an unrelated word.

\section{Results}

The mean RTs for correct trials and error rates for Experiment 4 are presented in Table 4 . These means exclude the $1.0 \%$ of the trials that failed to meet our criterion. Repeated measures ANOVAs were performed on the RT and error rate data.

The response time ANOVA indicated a marginally significant effect of condition, with mean RTs of 681 , 673 , and $698 \mathrm{msec}$ in the SO, DO, and NM conditions, respectively $\left[F_{1}(2,46)=2.8, M S_{\mathrm{e}}=2,657, p<.10\right.$; $\left.F_{2}(2,118)=1.9, M S_{\mathrm{e}}=10,164, p>.10\right]$. Mean RTs were significantly faster when the target appeared in the top frame (mean RT $=633 \mathrm{msec}$ ) than in the bottom frame $($ mean RT $=735 \mathrm{msec})\left[F_{1}(1,23)=94.8, M S_{\mathrm{e}}=3,981\right.$, $\left.p<.001 ; F_{2}(1,59)=87.3, M S_{\mathrm{e}}=11,611, p<.001\right]$. There was no interaction between condition and location $\left[F_{1}(2,46)=2.3, M S_{\mathrm{e}}=3,053, p>.10 ; F_{2}(2,118)=1.9\right.$, $\left.M S_{\mathrm{e}}=9,325, p>.10\right]$.

Of primary interest, of course, was whether or not object-specific and nonspecific preview effects would be 


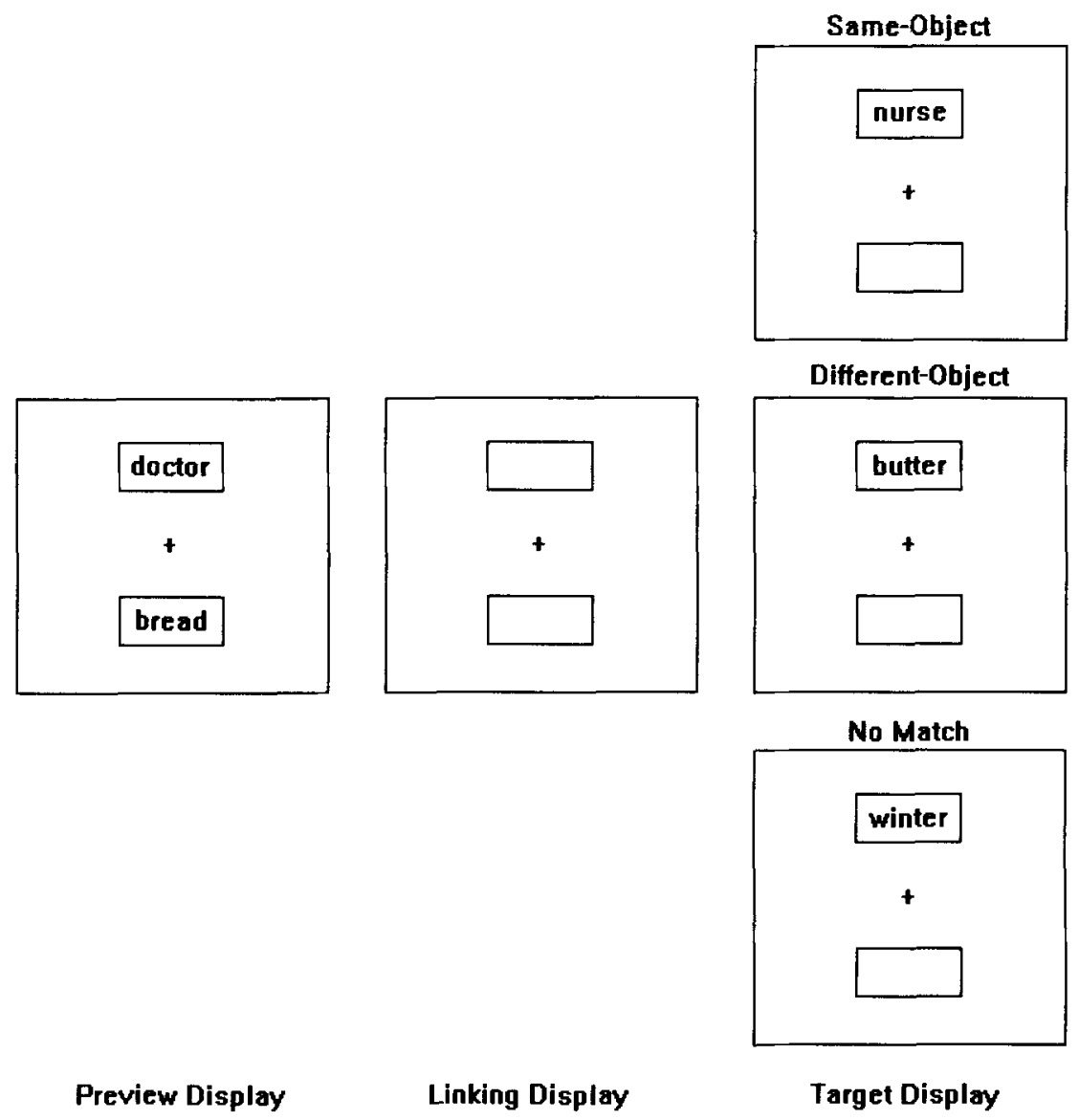

Figure 3. Example of displays used in Experiment 4.

found. As in previous experiments, there was evidence of a nonspecific preview benefit. Subjects responded more quickly when the target word was related to the preview word in the opposite frame (mean RT $=673 \mathrm{msec}$ ) than they did when the target word was unrelated to either preview word (mean RT $=698 \mathrm{msec})\left[F_{1}(1,23)=5.4\right.$, $M S_{\mathrm{e}}=2,657, p<.05 ; F_{2}(1,59)=3.6, M S_{\mathrm{e}}=10,164$, $p<.10]$. This suggests that previewing a related word facilitated responding to a target word. In other words, this result confirms that semantic priming occurred in the experiment. However, there was no object-specific preview

Table 4

Mean Response Times (RT) and Preview Effects (in Milliseconds), With Error Rates, in Experiment 4

\begin{tabular}{|c|c|c|c|c|c|c|}
\hline \multirow[b]{3}{*}{ Condition } & \multicolumn{6}{|c|}{ Target Location } \\
\hline & \multicolumn{2}{|c|}{ Top } & \multicolumn{2}{|c|}{ Bottom } & \multicolumn{2}{|c|}{ Overall } \\
\hline & RT & $\% \mathrm{E}$ & RT & $\% \mathrm{E}$ & RT & $\% \mathrm{E}$ \\
\hline Same object & 616 & 5.0 & 745 & 2.5 & 681 & 3.8 \\
\hline Different object & 624 & 2.1 & 722 & 3.8 & 673 & 3.0 \\
\hline No match & 657 & 4.6 & 738 & 6.3 & 698 & 5.5 \\
\hline$M$ & 634 & 3.9 & 735 & 4.2 & 684 & 4.1 \\
\hline \multicolumn{7}{|c|}{ Preview Effects } \\
\hline Object specific & 8 & -2.9 & -23 & 1.3 & -8 & -.8 \\
\hline Nonspecific & 33 & 2.5 & 16 & 2.5 & 25 & 2.5 \\
\hline
\end{tabular}

benefit; in fact, subjects responded more quickly in the DO condition (mean RT $=673 \mathrm{msec}$ ) than in the SO condition (mean RT $=681 \mathrm{msec}$ ), although this effect did not approach significance $\left[F_{1}(1,23)<1, M S_{\mathrm{e}}=2,657\right.$; $\left.F_{2}(1,59)<1, M S_{\mathrm{e}}=10,164\right]$. The $95 \%$ confidence interval for this comparison was $8 \pm 22$ msec.

The results of the error rate ANOVA indicated a marginally significant effect of condition $\left[F_{1}(2,46)=2.5\right.$, $M S_{\mathrm{e}}=0.003, p<.10 ; F_{2}(2,118)=2.3, M S_{\mathrm{e}}=0.008$, $p>.10$, with error rates of $3.8 \%, 3 \%$, and $5.5 \%$ in the $\mathrm{SO}, \mathrm{DO}$, and NM conditions, respectively. There was no main effect of location $\left[F_{1}(1,23)<1, M S_{\mathrm{e}}=0.005\right.$; $\left.F_{2}(1,59)<1, M S_{e}=0.01\right]$. There was a marginal interaction of condition $\times$ location $\left[F_{1}(2,46)=2.6, M S_{\mathrm{e}}=\right.$ $\left.0.003, p<.10 ; F_{2}(2,118)=2.0, M S_{\mathrm{e}}=0.009, p>.10\right]$. The nature of this interaction was that subjects tended to be more accurate in the SO condition on those trials in which the target appeared in the bottom frame (mean error rate $=2.5 \%$ ) rather than the top frame (mean error rate $=5.0 \%$ ), and they tended to be more accurate in the DO condition when the target appeared in the top frame (mean error rate $=2.1 \%$ ) rather than the bottom frame (mean error rate $=3.8 \%$ ). In both the DO top condition and the SO bottom condition, the relevant preview word appeared in the bottom frame. Thus this interaction sug- 
gests that subjects may have benefited from the bottom preview word more than from the top preview word, perhaps because they adopted a viewing strategy in which they read the bottom word last.

As with the RT ANOVA, there was evidence of a nonspecific preview effect on error rates. Subjects made fewer errors when the target word was related to the preview word in the opposite frame (mean error rate $=3.0 \%$ ) than when it was an unrelated word (mean error rate $=5.5 \%$ ) $\left[F_{1}(1,23)=5.0, M S_{\mathrm{e}}=0.003, p<.05 ; F_{2}(1,59)=4.7\right.$, $\left.M S_{\mathrm{e}}=0.008, p<.05\right]$. However, there was no evidence of an object-specific preview benefit. Subjects actually tended to be more accurate in the DO condition (mean error rate $=3.0 \%$ ) than in the SO condition (mean error rate $=3.8 \%$ ), although this difference was not significant $\left[F_{1}(1,23)<1, M S_{\mathrm{e}}=0.003 ; F_{2}(1,59)<1, M S_{\mathrm{e}}=0.008\right]$.

\section{Discussion}

Experiments 1-3 provided evidence that object files include information about object identity. The purpose of Experiment 4 was to determine whether object files also include the identities of related objects. There was evidence of general semantic priming; subjects responded more quickly and more accurately when the target word was related to one of the words in the preview display. However, there was no evidence that semantic information was bound to a particular object or location. Subjects responded equally quickly and accurately in the sameand different-object conditions. This result strongly suggests that this type of semantic information is not included in the object files that were created when subjects viewed the preview display.

However, this does not preclude the possibility that other types of semantic information may be included in object files. It may not be particularly useful to represent related items in a file for an object; it is more compelling to suppose that information about the semantic features of an object is included in its file. Some of the paired associates in Experiment 4 (e.g., tea and coffee) shared semantic features, but others (e.g., leaf and rake) did not. In our next experiment, we tested for the presence of information about the semantic features of an object in its object file.

\section{EXPERIMENT 5}

In Experiment 5, the preview-target pairs were synonyms, which by definition share many semantic features. If semantic features are included in an object file, lexical decision to a word should be faster if its synonym, with which it shares semantic features, is presented within the same frame in the preview display, than if it is presented in the opposite frame.

\section{Method}

Subjects. Twenty-four subjects participated for course credit.

Stimuli. The stimuli consisted of 360 words and 72 nonwords. The words included 68 synonym pairs ( 60 for the experimental trials and 8 for practice trials) that had previously been shown to have a high degree of similarity (Whitten, Suter, \& Frank, 1979). The target words had a mean frequency of 143 per million $(S D=147)$, and the preview words had a mean frequency of 126 per million $(S D=142)$ (Francis \& Kučera, 1982). As in Experiment 4, each subject saw each target exactly once. Across subjects, each target appeared in every condition and location. To achieve this design, six stimulus lists were created, as in Experiment 4; each list specified the condition and location for every target item, as well as the preview items for that target. Each list was presented to 4 subjects. For the SO and DO conditions, the preview items consisted of a word that was synonymous with the target and a word that was not synonymous with either the target word or the other preview word. For the NM condition, the preview items were 2 words that were not synonymous with each other or with the target word. The synonym pairs used are listed in Appendix B.

Apparatus. The apparatus was the same as in Experiment 1. Procedure. Examples of displays used in Experiment 5 are shown in Figure 4. The procedure was the same as in Experiment 1.

As in previous experiments, there were three conditions for the word trials. In the SO condition, the target word was synonymous with the preview word that had been displayed in the same frame. In the DO condition, the target word was synonymous with the preview word that had previously been displayed in the other frame. In the NM condition, the target word was not synonymous with either preview word.

\section{Results}

The mean RTs for correct trials and error rates for Experiment 5 are presented in Table 5 . These means exclude the $0.5 \%$ of the trials that failed to meet our criterion. Repeated measures ANOVAs were performed on the RT and error rate data.

The RT ANOVA indicated a significant effect of condition, with mean RTs of 676,662 , and $688 \mathrm{msec}$ in the SO, DO, and NM conditions, respectively $\left[F_{1}(2,46)=3.6\right.$, $M S_{\mathrm{e}}=2,252, p<.05 ; F_{2}(2,118)=2.5, M S_{\mathrm{e}}=7,282$, $p<.10]$. As was the case in previous experiments, there was a main effect of location; subjects responded more quickly when the target was presented in the top frame (mean RT $=636 \mathrm{msec}$ ) than when it was presented in the bottom frame (mean RT $=714 \mathrm{msec})\left[F_{1}(1,23)=31.1\right.$, $M S_{\mathrm{e}}=7,030, p<.001 ; F_{2}(1,59)=78.3, M S_{\mathrm{e}}=7,036$, $p<.001]$. Condition and location did not interact $\left[F_{1}(2,46)\right.$ $\left.<1, M S_{\mathrm{e}}=2,506 ; F_{2}(2,118)<1, M S_{\mathrm{e}}=9,713\right]$.

We were primarily interested in whether or not we would find evidence of nonspecific and object-specific preview effects. Consistent with the previous experiments, there was significant nonspecific priming: subjects responded more quickly when the target word was synonymous with the preview word in the opposite frame (mean $\mathrm{RT}=662 \mathrm{msec}$ ) than they did when the target word was not synonymous with either preview word (mean RT = $688 \mathrm{msec})\left[F_{1}(1,23)=7.2, M S_{\mathrm{e}}=2,252, p<.05\right]$, although this effect was not significant by items $\left[F_{2}(1,59)=\right.$ $\left.2.0, M S_{\mathrm{e}}=7,282, p>.10\right]$. This confirms that subjects did benefit from previewing a word that was synonymous with the target word. However, there was no objectspecific preview benefit; in fact, as in Experiment 4, subjects responded more quickly in the DO condition (mean $\mathrm{RT}=662 \mathrm{msec})$ than in the SO condition (mean RT = $676 \mathrm{msec}$ ), although this effect did not approach significance $\left[F_{1}(1,23)=2.0, M S_{\mathrm{e}}=2,252, p>.10 ; F_{2}(1,59)<1\right.$, $\left.M S_{\mathrm{e}}=7,282\right]$. The $95 \%$ confidence interval for this comparison was $14 \pm 20 \mathrm{msec}$. 


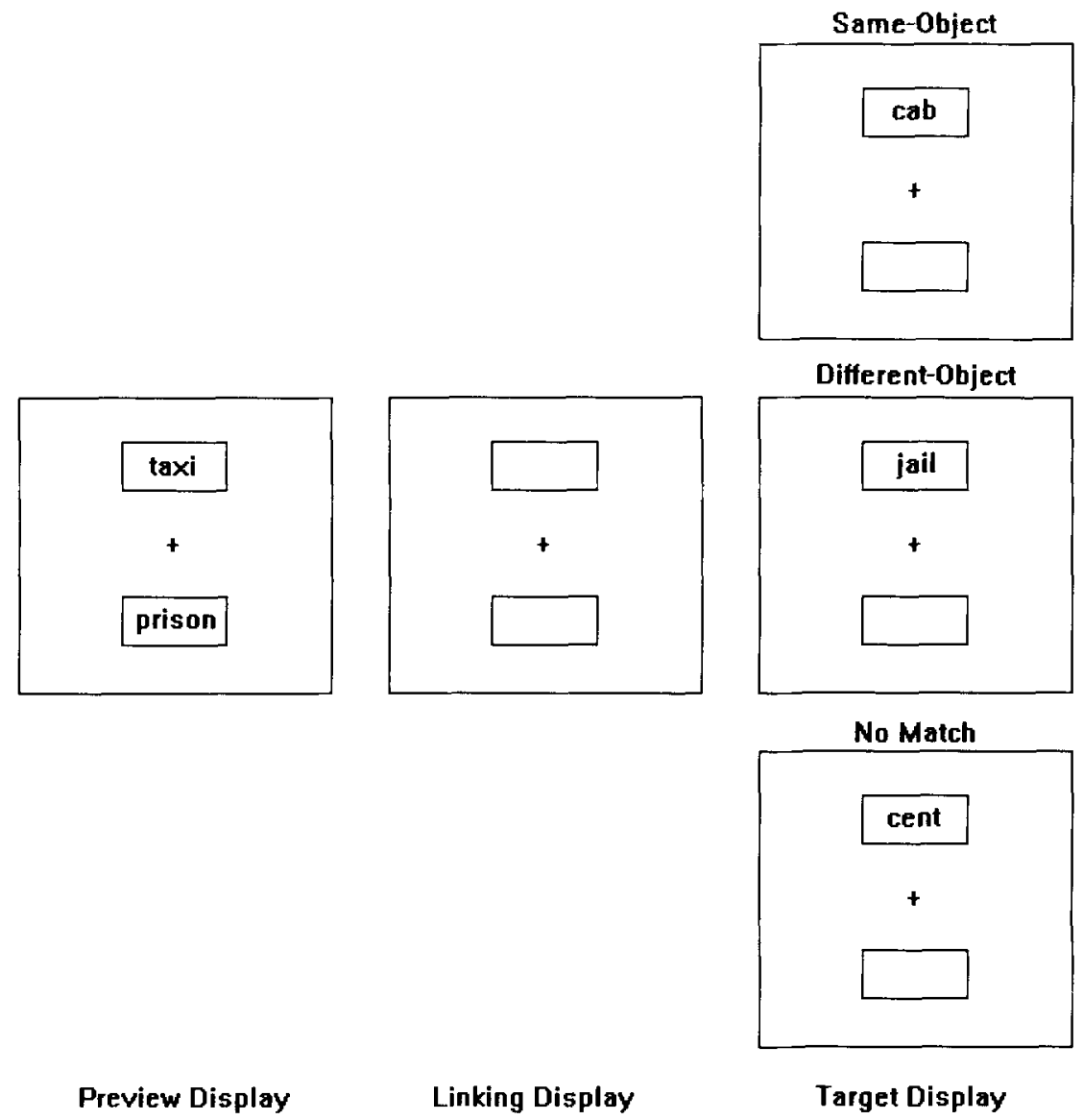

Figure 4. Example of displays used in Experiment 5.

The results of the error rate ANOVA indicated no significant effects of any of the experimental manipulations. There was no main effect of condition $\left[F_{1}(2,46)=\right.$ $\left.1.2, M S_{\mathrm{e}}=0.003, p>.30 ; F_{2}(2,118)<1, M S_{\mathrm{e}}=0.011\right]$ or of location $\left[F_{1}(1,23)=2.4, M S_{\mathrm{e}}=0.003, p>.10\right.$; $\left.F_{2}(1,59)=2.3, M S_{\mathrm{e}}=0.009, p>.10\right]$, and these variables did not interact $\left[F_{1}(2,46)=2.5, M S_{\mathrm{e}}=0.003, p>\right.$ $\left..05 ; F_{2}(2,118)=2.6, M S_{\mathrm{e}}=0.007, p>.05\right]$. Planned comparisons indicated that there was no object-specific preview effect $\left[F_{1}(1,23)<1, M S_{\mathrm{e}}=0.003 ; F_{2}(1,59)<1\right.$, $\left.M S_{\mathrm{e}}=0.011\right]$ or nonspecific preview effect $\left[F_{1}(1,23)<1\right.$, $\left.M S_{\mathrm{e}}=0.003 ; F_{2}(1,59)<1, M S_{\mathrm{e}}=0.011\right]$ on error rates.

Table 5

Mean Response Times (RT) and Preview Effects (in Milliseconds), With Error Rates, in Experiment 5

\begin{tabular}{|c|c|c|c|c|c|c|}
\hline \multirow[b]{3}{*}{ Condition } & \multicolumn{6}{|c|}{ Target Location } \\
\hline & \multicolumn{2}{|c|}{ Top } & \multicolumn{2}{|c|}{ Bottom } & \multicolumn{2}{|c|}{ Overall } \\
\hline & $\overline{\mathrm{RT}}$ & $\% \overline{\mathrm{E}}$ & $\mathrm{RT}$ & $\% \mathrm{E}$ & $\mathrm{RT}$ & $\% \mathrm{E}$ \\
\hline Same object & 638 & 0.8 & 714 & 4.2 & 676 & 2.5 \\
\hline Different object & 620 & 4.2 & 704 & 2.9 & 662 & 3.6 \\
\hline No match & 652 & 2.9 & 725 & 5.4 & 688 & 4.2 \\
\hline$M$ & 636 & 2.6 & 714 & 4.2 & 675 & 3.4 \\
\hline \multicolumn{7}{|c|}{ Preview Effects } \\
\hline Object specific & -18 & 3.4 & -10 & -1.3 & -14 & 1.1 \\
\hline Nonspecific & 32 & -1.3 & 21 & 2.5 & 26 & 0.6 \\
\hline
\end{tabular}

\section{Discussion}

The results from Experiment 5 suggest that information about the semantic features of an object are not included in its object file. This, along with the results of Experiment 4, provides support for the argument that semantic information in general is not included in object files. To provide further support, we next tested whether information about the category to which an object belongs may be included in its object file.

\section{EXPERIMENT 6}

In Experiment 6, the preview display on each trial consisted of two words (e.g., iron and robin), and the target display contained a single category name (e.g., metal). The subjects' task was to indicate whether or not either preview word was a member of the target category. If information about the category to which each preview word belongs is included in its object file, we should find evidence of object-specific preview benefits, because the target category should be identified more quickly when it appears in the same frame as one of its exemplars than when it appears in a different frame. We also varied the typicality of the preview word. For example, if the target word was bird, a preview word might be a typical (e.g., robin) or an atypical (e.g., penguin) exemplar of that cat- 
egory. We reasoned that, if there was any advantage to previewing a category member before responding to the category, RTs should be faster when the preview word was a typical exemplar than when it was an atypical exemplar (Collins \& Quillian, 1969). This manipulation therefore allowed us to test for the presence of a general priming effect.

\section{Method}

Subjects. There were 40 subjects, who participated for course credit.

Stimuli. The stimuli consisted of 420 words. Those included 72 target categories ( 60 for the experimental block, plus 12 for the practice block), plus a typical and an atypical exemplar of each. The categories and exemplars were selected from previously established norms of typicality (Battig \& Montague, 1969; Shapiro \& Palermo, 1970). The remaining 204 words were filler words, used to construct the preview displays. The mean written frequency was 124 per million $(S D=229)$ for the target categories, 141 per million $(S D=457)$ for the typical preview word, and 15 per million $(S D=34)$ for the atypical preview word (Francis \& Kučera, 1982). Each subject saw each target category exactly twice. Across subjects, each target appeared with each exemplar in every condition and location. To achieve this design, eight stimulus lists were created; each list specified the condition and location for every target item, as well as the preview items for that target. Each list was therefore presented to 5 subjects.

For the SO and DO conditions, the preview items consisted of one exemplar of the target category and one word that was not an exemplar of any target category, but that was a plausible exemplar (i.e., the preview word was an exemplar of a category not included in the experiment). For the NM condition, the preview items were two words that were not members of any target categories used in the experiment. Because, across subjects, each target category occurred in every condition, the target in the NM trials was always a name of a category. For some lists, a given category was preceded by a different one of its exemplars both times it was presented (SO or DO trials); for other lists, it was preceded by one of its exemplars for one presentation (SO or $\mathrm{DO}$ ), but it was not preceded by either of its exemplars for the other presentation (NM); for the remaining lists, the category was never preceded by one of its exemplars (NM). For each list, there was an equal number of target categories appearing in each condition. The word stimuli are listed in Appendix C.

Apparatus. The apparatus was the same as in Experiment 1.

Procedure. Examples of displays used in Experiment 6 are shown in Figure 5. The procedure was similar to that of the previous experiments, except that rather than presenting a word or nonword for lexical decision, a single category name was presented until a response was made. The subject's task was to press one microswitch if either preview word was a member of the target category, and the other microswitch if neither was a member.

As in the previous experiments, there were three main conditions. In the SO condition, the preview word that was presented in the same frame as the target category was a member of that category. In the DO condition, the preview word that was presented in the other frame was a member of the target category. In the NM condition, neither preview word was a member of the target category. Note that, in this experiment, correct performance in the NM condition requires a negative response, whereas correct performance in the other conditions requires a positive response. For this reason, it was not meaningful to compare RTs between the NM and DO conditions as a measure of nonspecific preview effects. So, as mentioned in the introduction to this experiment, to measure this general priming we used typical and atypical exemplars as preview words for each target category. For example, on a trial in which the target category was bird, the preview word could be either robin (a typical exemplar) or penguin (an atypical exemplar).

\section{Results}

The mean RTs for correct trials and error rates for Experiment 6 are presented in Table 6 . These means exclude the $1.8 \%$ of the trials that failed to meet our criterion. Repeated measures ANOVAs were performed on the RT and error rate data.

The RT ANOVA indicated no reliable effect of condition, with mean RTs of 861 and $873 \mathrm{msec}$ in the SO and DO conditions, respectively $\left[F_{1}(1,39)=1.2, M S_{\mathrm{e}}=\right.$ $\left.8,328, p>.25 ; F_{2}(1,118)<1, M S_{\mathrm{e}}=41,237\right]$. The $95 \%$ confidence interval for this comparison was $12 \pm 29 \mathrm{msec}$. Thus it appears that there was no reliable object- or location-specific preview benefit in this experiment. There was a main effect of location; subjects responded more quickly when the target was presented in the top frame (mean RT $=831 \mathrm{msec}$ ) than when it was presented in the bottom frame (mean RT $=902 \mathrm{msec})\left[F_{1}(1,39)=\right.$ $44.1, M S_{\mathrm{e}}=9,160, p<.001 ; F_{2}(1,118)=15.1, M S_{\mathrm{e}}=$ $36,024, p<.001]$. There was also a main effect of the typicality of the priming word: subjects responded more quickly when the preview word was a typical member of the target category (mean RT $=824 \mathrm{msec}$ ) than when it was less typical of the target category (mean RT = $909 \mathrm{msec})\left[F_{1}(1,39)=29.5, M S_{\mathrm{e}}=19,503, p<.001\right.$; $\left.F_{2}(1,118)=9.2, M S_{\mathrm{e}}=80,644, p<.005\right]$. This suggests that subjects were deriving some nonspecific benefit from the preview of a member of the target category. There were no interactions either between condition and location $\left[F_{1}(1,39)<1, M S_{\mathrm{e}}=12,661 ; F_{2}(1,118)<1, M S_{\mathrm{e}}=\right.$ $55,435]$, condition and typicality $\left[F_{1}(1,39)<1 ; M S_{\mathrm{e}}=\right.$ $\left.11,848.8 ; F_{2}(1,118)<1, M S_{\mathrm{e}}=41,237\right]$, location and typicality $\left[F_{1}(1,39)=2.5, M S_{\mathrm{e}}=12,131, p>.10 ; F_{2}(1,118)=\right.$ $\left.1.1, M S_{\mathrm{e}}=36,024, p>.25\right]$, or among all three factors $\left[F_{1}(1,39)<1, M S_{\mathrm{e}}=11,441 ; F_{2}(1,118)=1.0, M S_{\mathrm{e}}=\right.$ $55,435, p>.30]$.

The results of the error rate ANOVA were generally consistent with the RT analyses. There was no main effect of condition $\left[F_{1}(1,39)=2.3, M S_{\mathrm{e}}=0.013, p>.10\right.$; $\left.F_{2}(1,118)=3.1, M S_{\mathrm{e}}=0.014, p>.05\right]$ or of location $\left[F_{1}(1,39)<1, M S_{\mathrm{e}}=0.011 ; F_{2}(1,118)=1.0, M S_{\mathrm{e}}=\right.$ $0.014, p>30$ ], but there was an effect of the typicality of the preview word, with mean error rates of $5.6 \%$ and $14.4 \%$ in the typical and atypical preview conditions, respectively $\left[F_{1}(1,39)=44.8, M S_{\mathrm{e}}=0.014, p<.001\right.$; $\left.F_{2}(1,118)=14.1, M S_{\mathrm{e}}=0.065, p<.001\right]$. There was a significant condition by location interaction; subjects were more accurate in the DO condition when the target appeared in the top frame (mean error rate $=9.0 \%$ ) than in the bottom frame (mean error rate $=10.1 \%$ ), and they were more accurate in the SO condition when the target appeared in the bottom frame (mean error rate $=8.1 \%$ ) than in the top frame (mean error rate $=13.0 \%)\left[F_{1}(1,39)\right.$ $=6.8, M S_{\mathrm{e}}=0.011, p<.05 ; F_{2}(1,118)=5.7, M S_{\mathrm{e}}=$ $0.018, p<.05]$. This interaction is similar to that observed 


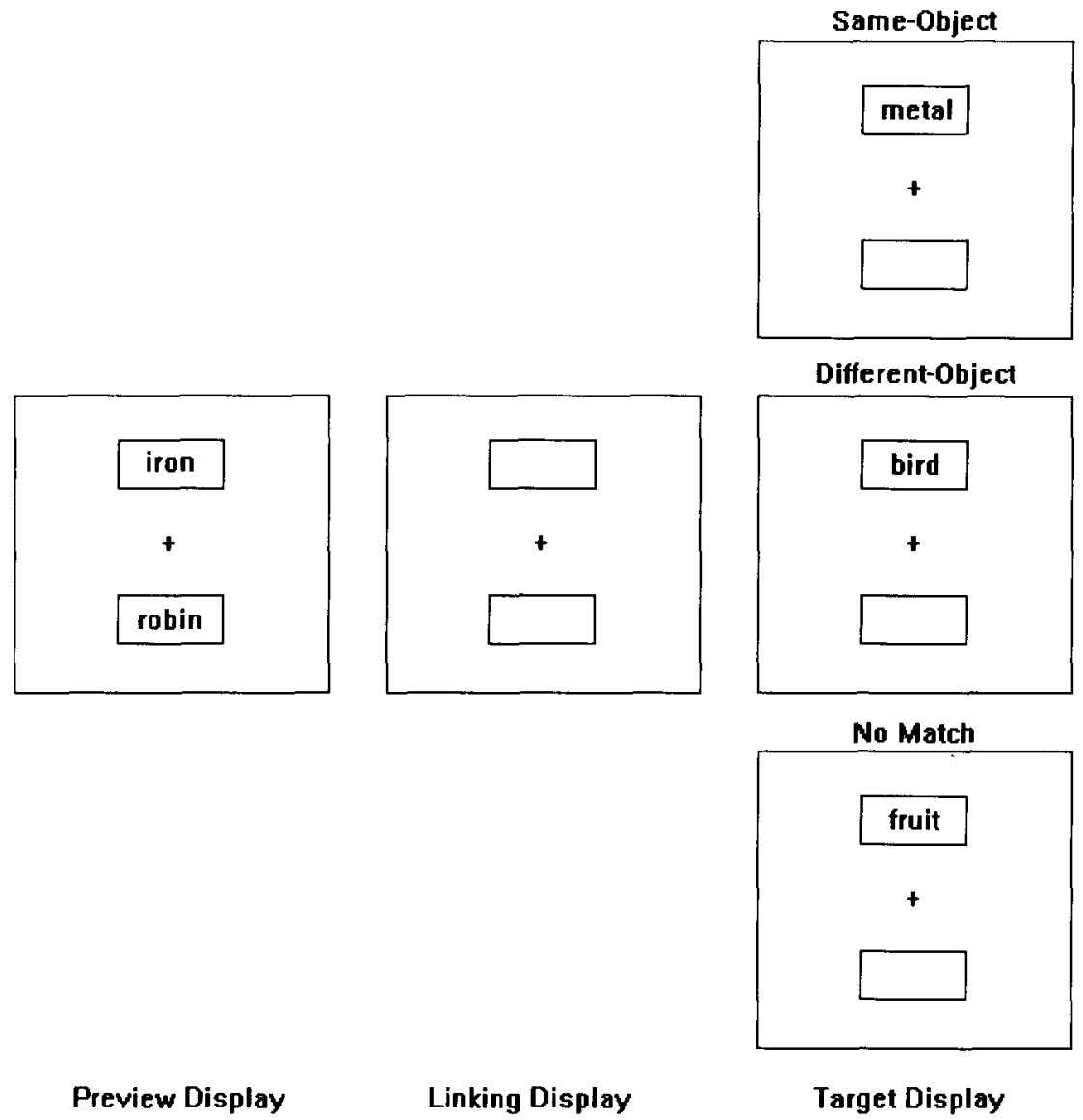

Figure 5. Example of displays used in Experiment 6.

in the error rates for Experiment 4. As in Experiment 4, we suggest that the interaction may reflect a viewing strategy in which subjects read the bottom word last. None of the other interactions was significant (all $F_{\mathrm{s}}<1$ ).

\section{Discussion}

If information about the category to which an object belongs is included in its object file, we would expect to find object-specific preview benefits in responses made

Table 6

Mean Response Times (RT) and Preview Effects (in Milliseconds), With Error Rates, in Experiment 6

\begin{tabular}{|c|c|c|c|c|c|c|}
\hline \multirow[b]{3}{*}{ Condition } & \multicolumn{6}{|c|}{ Target Location } \\
\hline & \multicolumn{2}{|c|}{ Top } & \multicolumn{2}{|c|}{ Bottom } & \multicolumn{2}{|c|}{ Overall } \\
\hline & RT & $\% \mathrm{E}$ & RT & $\% \mathrm{E}$ & RT & $\% \mathrm{E}$ \\
\hline Same object & 831 & 10.1 & 891 & 8.1 & 861 & 9.1 \\
\hline Typical & 808 & 5.0 & 839 & 3.7 & 824 & 4.4 \\
\hline Atypical & 854 & 15.1 & 944 & 12.5 & 899 & 13.8 \\
\hline Different object & 832 & 9.0 & 913 & 13.0 & 873 & 11.0 \\
\hline Typical & 789 & 4.6 & 862 & 9.2 & 826 & 6.9 \\
\hline Atypical & 874 & 13.3 & 965 & 16.8 & 920 & 15.1 \\
\hline$M$ & 831 & 9.5 & 902 & 10.6 & $86 ?$ & 10.1 \\
\hline \multicolumn{7}{|c|}{ Preview Effects } \\
\hline Object specific & 1 & -1.1 & 22 & 4.9 & 12 & 1.9 \\
\hline Typicality & 66 & 9.4 & 104 & 8.2 & 85 & 8.8 \\
\hline
\end{tabular}

to a target category; however, no evidence of such a benefit was found in Experiment 6 . This is despite the fact that the task demands required subjects to attend to the category to which each preview item belonged, and despite the fact that we found evidence of nonspecific preview benefits. Thus it appears that information about category membership is not included in object files.

\section{GENERAL DISCUSSION}

The purpose of the present investigation was to identify whether certain types of information about an object are included in its object file. Treisman and her colleagues have suggested that all information that defines an object is included in its object file, including identity and meaning. In the experiments described here, we used a priming paradigm to test for the presence of specific types of information in object files. The logic was this: if some aspect of an object is included in its object file, subjects should be primed to respond to that aspect for that object. In Experiments 1 and 2, subjects responded to a target item that was identical to the word that had been previewed within the same object, previewed within another object, or not previewed at all. If the identity of the word was included in its object file, subjects should have responded more quickly to it when it was identical to the 
SO preview than when it was identical to the DO preview. In fact, this is what was found, providing evidence that information about object identity is included in object files. It should be noted, however, that the object-specific effects observed in Experiment 2 (in which the objects changed location during the linking display) were only marginal; it is likely that the effects we reported in Experiment 1 reflected both an object-specific advantage and a location-specific advantage.

Although the results of Experiments 1 and 2 suggested that object files include identity information, an alternative explanation was that the physical form, and not the identity, of the preview objects was being stored in their object files, and that the location-specific or objectspecific preview effects we observed were the result of shape consistency, not identity consistency, between the two displays. In Experiment 3, we reduced the form similarity between the preview and target displays by changing the case in which the items were printed. The results indicated that changing the physical form of the stimuli did not eliminate, or even reduce, the object- or locationspecific preview benefit. This supports the argument that object files contain an abstract identity code for the objects that they represent.

In Experiment 4, the target item was no longer identical in name to a preview item, but instead could be related to the SO preview word, related to the DO preview word, or unrelated to either preview word. The logic here was the same as in the previous experiments: if related items are also included in object files, subjects should respond more quickly to related words that are presented within the same object than to those that are presented within another object. This is not the pattern of results that was obtained, however. Mean RTs did not differ between the SO and DO conditions. This suggests that one type of semantic information - namely, information about related words or objects--is not included in an object file that represents a word.

In Experiment 5, we tested whether information about the semantic features of an object is included in its object file. To test this, we used synonyms as prime-target pairs. Synonyms share semantic features; thus, if semantic features are stored in an object file that represents a word, response latencies should be shorter when subjects preview a synonymous word in the same frame than when they preview it within a different frame. However, the results suggested that semantic features are not stored in object files; RTs did not differ between the same- and different-object conditions, despite the fact that subjects did benefit from nonspecific priming.

It is interesting to note that in both Experiments 4 and 5 there was a nonsignificant trend for subjects to respond more quickly in the DO condition than in the SO condition, counter to expectation. Although the effect was not statistically significant, it is interesting that it was present in both experiments, and also in other experiments, not reported here, in which we have tested for the presence of semantic information in object files. This con- sistent result may reflect a weak inhibitory component in the storage of information in object files, a suggestion that we are following up on in our laboratory.

Finally, in Experiment 6, we tested for the presence in object files of information about the category to which an object belongs. In addition to testing for category information, this experiment also required subjects to attend to the words in the preview display, because accurate task performance required integrating information in the preview and target displays. If attention to some feature of an object is a necessary precursor to its being included in an object file, we should expect to find evidence for category information in object files. However, despite the fact that subjects were consciously attending to the category to which each preview item belonged, there was no evidence that this information was being stored in object files.

One result that was consistently obtained in the experiments was an advantage in RT and error rate when the target word was presented in the top location. We have attributed this result to a bias to attend to the top location in the target display, a bias that may result from typical reading behavior. Although this result was obtained for nearly every condition in every experiment, it was not found for the error rates in Experiments 4 and 6 . In those experiments, subjects were more accurate when the target appeared in the bottom location in the SO condition, and in the top location in the DO condition. We suggested that in this case, subjects were more accurate when the target was a repetition of the bottom preview word, perhaps because they previewed that word last; thus, in this case, performance accuracy seems to have been driven by an advantage of one preview location over the other. However, aside from those two exceptions, performance in these experiments cannot be attributed to an advantage of one preview location over another in influencing processing; rather, as predicted by object file theory, performance seems to be attributable to an advantage when the location of the target matches its location within the preview display.

Overall, then, these results suggest that information about the identity of objects is stored in object files, but at least three types of semantic information (related concepts, semantic features, and category membership) are not. Moreover, the results of Experiment 3 suggest that identity is stored as an abstract description of the object.

Object files have become popular as a way of describing the episodic representations of objects that are important for maintaining object continuity across change. However, very little has been written about what information is actually stored as part of this representation. In the present investigation, we have argued that some types of semantic information are not stored in object files, and we have suggested some types of physical or abstract information that may be included. Without a description of the nature of the object file representation itself, object files are little more than a convenient way of describing an interesting result. If the nature of what is stored is un- 
derstood, we will have gained better insight into the nature of object perception and representation.

\section{REFERENCES}

BALOTA, D. A., \& LORCH, R. F. (1986). Depth of automatic spreading activation: Mediated priming effects in pronunciation but not in lexical decision. Journal of Experimental Psychology: Learning, Memory, \& Cognition, 12, 336-345.

Battig, W. F., \& Montague, W. E. (1969). Category norms for verbal items in 56 categories: A replication and extension of the Connecticut category norms. Journal of Experimental Psychology, 80(3, Pt. 2).

BAYLIS, G. C. (1994). Visual attention and objects: Two-object cost with equal convexity. Journal of Experimental Psychology: Human Perception \& Performance, 20, 208-212.

BAyLIS, G. C., \& Driver, J. (1993). Visual attention and objects: Evidence for hierarchical coding of locations. Journal of Experimental Psychology: Human Perception \& Performance, 19, 451-470.

Collins, A. M., \& Quillian, M. R. (1969). Retrieval time from semantic memory. Journal of Verbal Learning \& Verbal Behavior, 8, 240-247.

DUNCAN, J. (1984). Selective attention and the organization of visual information. Journal of Experimental Psychology: General, 113, 501-517.

FISCHLER, I. (1977). Semantic facilitation without association in a lexical decision task. Memory \& Cognition, 5, 335-339.

Francis, W. N., \& Kučera, H. (1982). Frequency analysis of English usage: Lexicon and grammar. Boston: Houghton Mifflin.

HENDERSON, J. M. (1994). Two representational systems in dynamic visual identification. Journal of Experimental Psychology: General, $123,410-426$.

Henderson, J. M., \& ANes, M. D. (1994). Roles of object-file review and type priming in visual identification within and across eye fixations. Journal of Experimental Psychology: Human Perception \& Performance, 20, 826-839.

Kahneman, D., \& Treisman, A. (1984). Changing views of attention and automaticity. In R. Parasuraman \& D. R. Davies (Eds.), Varieties of attention (pp. 29-61). New York: Academic Press.

Kahneman, D., Treisman, A., \& GibBs, B. J. (1992). The reviewing of object files: Object-specific integration of information. Cognitive Psychology, 24, 175-219.
Kramer, A. F, \& Jacobson, A. (1991). Perceptual organization and focused attention: The role of objects and proximity in visual processing. Perception \& Psychophysics, 50, 267-284.

Lesch, M. F., \& Pollatsek, A. (1993). Automatic access of semantic information by phonological codes in visual word recognition. Journal of Experimental Psychology: Learning, Memory, \& Cognition, 19, 285-294.

LUPKER, S. J. (1984). Semantic priming without association: A second look. Journal of Verbal Learning \& Verbal Behavior, 23, 709733.

Meyer, D. E., \& Schyaneveldt, R. W. (1971). Facilitation in recognizing pairs of words: Evidence of a dependence between retrieval operations. Journal of Experimental Psychology, 90, 227-234.

Palermo, D. S., \& Jenkins, J. J. (1964). Word association norms. Minneapolis: University of Minnesota Press.

Pylyshyn, Z. (1989). The role of location indexes in spatial perception: A sketch of the FINST spatial-index model. Cognition, 32, 6597.

Sereno, J. A. (1991). Graphemic, associative, and syntactic priming effects at a brief stimulus onset asynchrony in lexical decision and naming. Journal of Experimental Psychology: Learning, Memory, \& Cognition, 17, 459-477.

ShapiRo, S. I., \& PALERMO, D. S. (1970). Conceptual organization and class membership: Normative data for representatives of 100 categories. Psychonomic Monograph Supplements, 3(11, Whole No. 43), 107-127.

Treisman, A. (1988). Features and objects: The Fourteenth Bartlett Memorial Lecture. Quarterly Journal of Experimental Psychology, 40A, 201-237.

Treisman, A. (1992). Perceiving and re-perceiving objects. American Psychologist, 47, 862-875.

Treisman, A., \& Gelade, G. (1980). A feature-integration theory of attention. Cognitive Psychology, 12, 97-136.

UNDERWOOD, G. (1976). Semantic interference from unattended printed words. British Journal of Psychology, 67, 327-338.

Whitten, W. B., Suter, W. N., \& Frank, M. L. (1979). Bidirectional synonym ratings of 464 noun pairs. Journal of Verbal Learning \& Verbal Behavior, 18, 109-127.

WOLFE, J. M. (1992). The parallel guidance of visual attention. Current Directions in Psychological Science, 1, 124-128. 
APPENDIX A

List of Word Stimuli Used in the Experimental Block of Experiments 1-4

Note: The replacement word replaces Preview 2 (the related preview item) on the no-match trials. In Experiments 1 and 2, Preview 2 was a repetition of the target word. The Preview 2 words listed here are for Experiment 4.

\begin{tabular}{|c|c|c|c|c|c|c|c|}
\hline Preview 1 & Preview 2 & Target & Replacement & Preview 1 & Preview 2 & Target & Replacement \\
\hline camel & summer & winter & style & cry & heavy & light & illusion \\
\hline lost & nurse & doctor & far & stove & needle & thread & paint \\
\hline volume & white & black & sort & birthday & rough & smooth & hang \\
\hline wrist & vanilla & chocolate & scene & stick & hammer & nail & direct \\
\hline knife & mosquito & bite & price & bat & grass & green & press \\
\hline hand & dream & sleep & late & head & termite & wood & mean \\
\hline ceiling & rake & leaf & put & editor & room & space & deal \\
\hline tooth & priest & church & told & zebra & pretty & ugly & agency \\
\hline school & cat & $\operatorname{dog}$ & block & enjoy & chair & table & pound \\
\hline ostrich & storm & rain & list & pants & plumber & pipe & visit \\
\hline hurt & jump & rope & due & breeze & apple & orange & frame \\
\hline valley & butterfly & moth & fix & dentist & author & book & motor \\
\hline ground & woman & $\operatorname{man}$ & choice & deer & afraid & scared & claim \\
\hline lettuce & pilot & plane & pool & gas & lion & tiger & stare \\
\hline foot & phone & number & demand & weight & cottage & house & parent \\
\hline harbor & nose & face & write & city & long & short & fund \\
\hline harpoon & sky & blue & turn & guest & war & peace & game \\
\hline oyster & truck & car & issue & lemon & boy & girl & close \\
\hline club & soap & water & design & train & king & queen & left \\
\hline beet & tea & coffee & force & sport & flower & rose & manner \\
\hline sleet & high & low & mark & reality & lock & key & return \\
\hline sea & hard & soft & pull & bit & vest & suit & theory \\
\hline month & sheep & wool & warning & stomach & bee & sting & region \\
\hline pen & day & night & average & crisis & beer & wine & hotel \\
\hline coat & moon & sun & save & drum & carrot & pea & date \\
\hline yam & beach & sand & spring & barbecue & smile & frown & listen \\
\hline wedding & salt & pepper & model & sound & penny & copper & prove \\
\hline navy & shave & razor & bad & win & river & stream & radio \\
\hline scissors & tree & maple & horse & spider & soldier & sailor & treat \\
\hline circle & steel & iron & wish & cold & sugar & sweet & fix \\
\hline
\end{tabular}

APPENDIX B

List of Synonym Pairs Used in the Experimental Block of Experiment 5

\begin{tabular}{|c|c|c|c|}
\hline Target & Preview & Target & Preview \\
\hline buy & purchase & applause & clapping \\
\hline lawyer & attorney & sight & vision \\
\hline fall & autumn & subject & topic \\
\hline cent & penny & promise & vow \\
\hline $\mathrm{cab}$ & $\operatorname{taxi}$ & baby & infant \\
\hline car & auto & area & region \\
\hline error & mistake & movie & film \\
\hline student & pupil & odor & smell \\
\hline present & gift & trip & journey \\
\hline teacher & instructor & crying & weeping \\
\hline result & outcome & prediction & forecast \\
\hline victory & triumph & forest & woodland \\
\hline basement & cellar & writer & author \\
\hline display & exhibit & money & currency \\
\hline consent & permission & opponent & rival \\
\hline comment & remark & nation & country \\
\hline middle & center & sunrise & dawn \\
\hline order & command & reduction & decrease \\
\hline jail & prison & gain & profit \\
\hline courage & bravery & reason & motive \\
\hline singer & vocalist & cloth & fabric \\
\hline rabbit & bunny & motor & engine \\
\hline murder & homicide & feeling & emotion \\
\hline defect & flaw & idea & concept \\
\hline total & sum & rug & carpet \\
\hline pair & couple & bug & insect \\
\hline dinner & supper & custom & tradition \\
\hline liquid & fluid & laborer & worker \\
\hline motion & movement & pilot & aviator \\
\hline freedom & liberty & important & vital \\
\hline
\end{tabular}


APPENDIX C

List of Category-Exemplar Pairs Used in the Experimental Block of Experiment 6

\begin{tabular}{|c|c|c|c|c|c|}
\hline \multirow[b]{2}{*}{ Target Category } & \multicolumn{2}{|c|}{ Preview } & \multirow[b]{2}{*}{ Target Category } & \multicolumn{2}{|c|}{ Preview } \\
\hline & Typical & Atypical & & Typical & Atypical \\
\hline metal & iron & nickel & instrument & piano & bassoon \\
\hline animal & $\operatorname{dog}$ & elk & country & france & chile \\
\hline cloth & cotton & flannel & weapon & gun & pipe \\
\hline color & blue & beige & number & one & $\operatorname{six}$ \\
\hline furniture & chair & cabinet & appliance & toaster & dryer \\
\hline fruit & apple & melon & liquid & water & alcohol \\
\hline dwelling & house & castle & month & june & november \\
\hline crime & murder & fraud & wood & maple & elm \\
\hline tool & hammer & crowbar & pet & cat & canary \\
\hline fuel & gas & propane & utensil & fork & plate \\
\hline profession & doctor & senator & relative & aunt & niece \\
\hline sport & football & polo & rodent & rat & gopher \\
\hline clothing & shirt & vest & seasoning & salt & nutmeg \\
\hline element & oxygen & lithium & juice & orange & prune \\
\hline money & dollar & shilling & reptile & lizard & iguana \\
\hline music & jazz & chamber & liquor & whiskey & rye \\
\hline bird & robin & penguin & meat & beef & venison \\
\hline vehicle & car & $\operatorname{taxi}$ & exercise & running & tennis \\
\hline science & chemistry & anatomy & composer & beethoven & handel \\
\hline toy & doll & wagon & painter & picasso & monet \\
\hline vegetable & carrot & turnip & jam & strawberry & apricot \\
\hline insect & fly & hornet & planet & mars & neptune \\
\hline flower & rose & marigold & emotion & love & sorrow \\
\hline disease & cancer & diabetes & novelist & hemingway & twain \\
\hline tree & oak & palm & language & french & greek \\
\hline fish & trout & halibut & seafood & lobster & salmon \\
\hline snake & rattler & viper & dessert & cake & cookies \\
\hline city & chicago & madrid & jewelry & ring & brooch \\
\hline state & illinois & wyoming & shape & circle & cube \\
\hline university & harvard & rutgers & scientist & einstein & curie \\
\hline
\end{tabular}

APPENDIX D

Nonwords Used in Experiments 1-5

(Including Practice Trials)

\begin{tabular}{llll}
\hline smed & spet & cron & sorneg \\
jarton & treper & donter & banten \\
corple & shoket & lurp & flink \\
gurkle & hestim & shiger & retis \\
blun & glant & rensor & calark \\
cubble & plef & vobget & sardel \\
offost & bolet & wootis & vapet \\
plarot & doot & strig & orkle \\
dosker & nanth & corbat & curfin \\
rull & terwin & soabit & croise \\
totor & maint & snait & odnice \\
troz & parbin & nouch & hilnet \\
mepsig & corth & blukin & lunter \\
dreat & riscut & bist & tramet \\
roaken & arfit & ostrem & biton \\
marlet & blent & plam & gultan \\
vorg & cloot & akment & preak \\
drig & miglen & peath & nustle \\
\hline
\end{tabular}

(Manuscript received June 21, 1995;

revision accepted for publication February 22, 1996.) 